\title{
El programa ornamental en la villa bajo imperial de el Saucedo (Talavera la Nueva, Toledo): Los Mármoles.
}

\author{
Raquel Castelo Ruano (Universidad Autónoma de Madrid); \\ Irene Seco (Universidad de Sant Louis y Cuerpo Facultativo de Conservadores de Museos) \\ Clara Bango García (Universidad Autónoma de Madrid).
}

\section{Resumen}

En este artículo abordamos el análisis y problemática del ciclo decorativo de la villa bajoimperial de El Saucedo. Como ya señalara Noguera Celdrán, estos estudios han motivado en los últimos años un creciente y renovado interés en el seno de la investigación arqueológica que se ha traducido en un incremento tanto cualitativo como cuantitativo de los estudios dedicados a su definición e interpretación (Noguera Celdrán, 2000, 111).

Con este estudio queremos rendir un sincero y merecido homenaje a la Dra. Lucas Pellicer quien dedicó parte de su investigación al análisis de los pavimentos musivarios y pintura mural documentadas en las villas romanas de Aguilafuente (Segovia) y La Torrecilla (Getafe, Madrid).

PALABRAS CLAVE: Ciclo decorativo, bajoimperial, villae

\section{Summary}

In this article we approach the analysis and problematic of the decorative cycle of the low-imperial villa of El Saucedo. As Noguera Celdrán already indicated, these studies have motivated in the last years an increasing and renewed interest in the archaeological investigation that has been translated to an increase, both qualitative and quantitative, of the studies dedicated to its definition and interpretation (Noguera Celdrán, 2000, 111).

With this study we want to pay a sincere and deserved homage to Dra. Lucas Pellicer who dedicated part of her investigation to the analysis of the mosaics and murals documented in the Roman villas of Aguilafuente (Segovia) and La Torrecilla (Getafe, Madrid).

KEYWORDS: Decorative cycle, low-imperial, villae

\section{I.- SituACión}

La villa se encuentra situada a menos de $1 \mathrm{~km}$ al norte de Talavera la Nueva (Toledo), junto al arroyo Baladíes o Albaladiel, dentro del municipio y comarca de Talavera de la Reina. Las coordenadas U.T.M. que localizan el yacimiento son $338750 \mathrm{E}$ y $4423450 \mathrm{~N}$ y aparecen en la hoja 626, Calera y Chozas, del Mapa Topográfico Nacional a escala 1:50.000. El enclave del yacimiento apenas rebasa los $360 \mathrm{~m}$ de altitud, con escaso resalte orográfico en el entorno, en plena llanura aluvial de la margen derecha del río Tajo y a $3 \mathrm{~km}$. escasos de distancia del curso actual. (Fig. 1.1 y 1.2 )

II.- LOS MÁRMOLES DE EL SAUCEDO. Placas PARA ReVESTIMIENTO PARIETAL y/o pavimental. Piezas escultoricas.

II.1.- Placas marmóreas para revestimientos parietales y pavimentales.

El revestimiento de las superficies parietales o pavimentales con placas de mármol u otros materiales lapídeos cortados en formas geométricas, vegetales e incluso figuradas, y ensambladas para obtener composiciones ornamentales, fue el tipo de recubrimiento más costoso y apreciado en época romana $y$, por tanto, menos habitual 


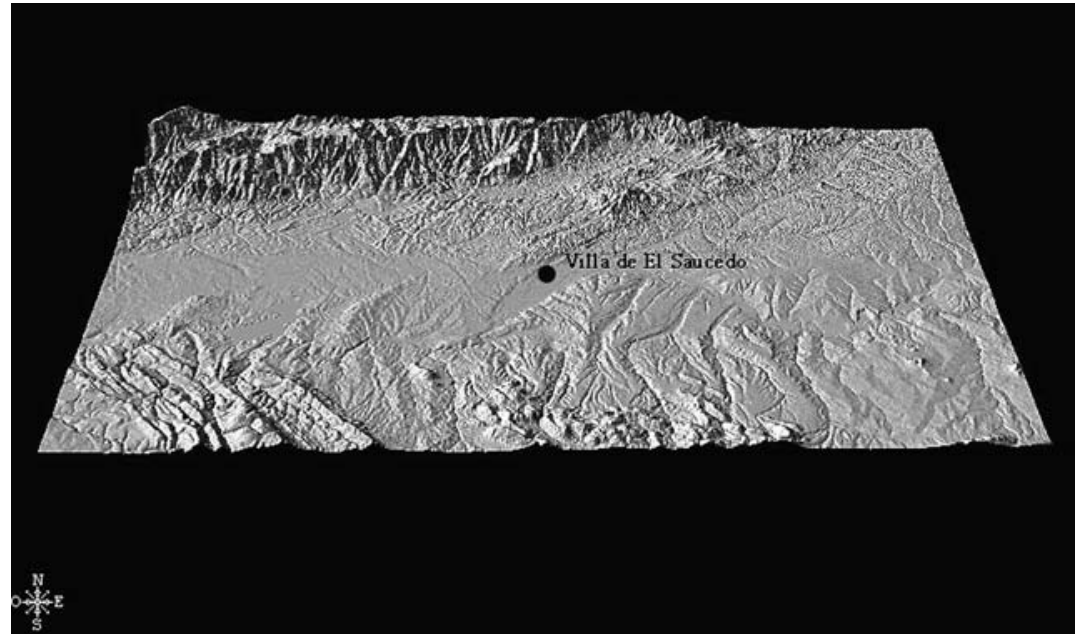

1.1. Plano con el Marco Geográfico. (M. Zamora)

Aunque el uso de revestimientos murales se remonta al II milenio a.C, habiéndose documentado en los ámbitos minoico-micénico y egipcio, su introducción en Roma se produce (según Plinio: Nat. Hist. 36, 48) con Mamurra, que revistió los muros de su casa con materiales importados. En Italia, este tipo de recubrimiento se puso de moda a partir de Augusto, ya que el princeps convirtió el mármol en emblema de la dignidad imperial romana.

En época altoimperial el uso del revestimiento parietal en la Península Ibérica se documenta

que otros tipos decorativos más populares como el mosaico o la pintura mural. El marmor fue el principal elemento utilizado para los suelos, aunque también se emplearon piedras menos nobles como calizas o pizarras, e incluso, en ocasiones, terracotas. En las paredes, además de los elementos citados también se emplearon la pasta vítrea, las piedras semipreciosas, el nácar, las conchas, etc. principalmente en las ciudades de la costa este peninsular y en el Valle del Ebro, así como en aquellos enclaves que juegan un destacado papel en la administración como por ejemplo, las capitales de provincia y las conventuales. Su uso también es frecuente en aquellas ciudades que están relacionadas con el aprovisionamiento de mármoles importados, localizados en la periferia peninsular y curso de ríos navegables,

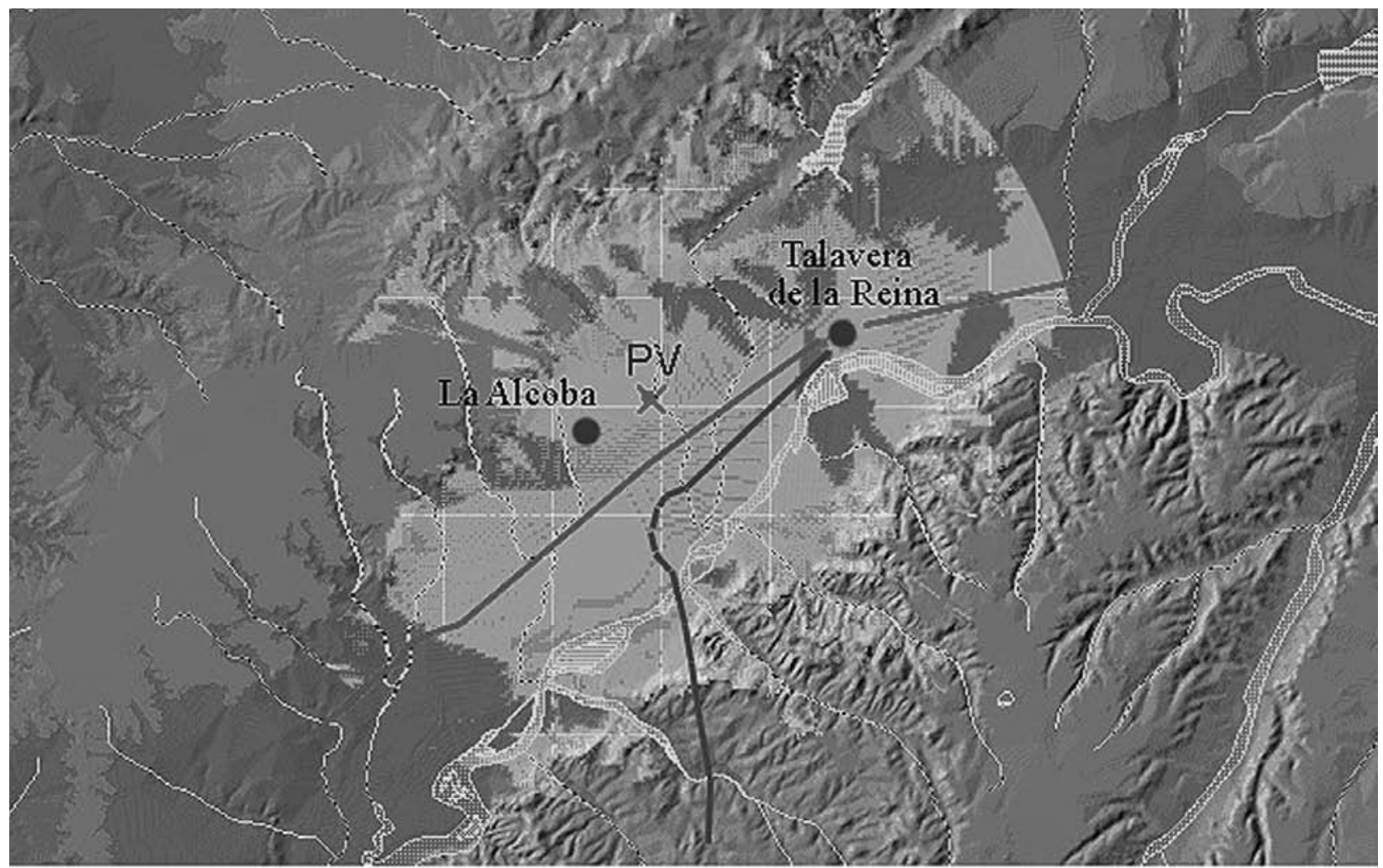

Area visible aproximada. Radio $=10 \mathrm{~km}$

Calzada romana a Augustobriga
PV = Punto de visión, Villa de El Saucedo

Via 25 Itinerario Antonino

1.2. Plano de visibilidad. (M. Zamora) 
y por otro, en zonas del interior próximas a los focos de extracción local. Para este momento existen importantes ejemplos procedentes de espacios públicos, pero son mayoritarios los adscritos a viviendas privadas (Pérez Olmedo, 1999, 335-341). La mayoría de los ejemplos de revestimientos parietales documentados en la península, corresponden al siglo IV d.C., y están atestiguados en importantes conjuntos rurales o suburbanos. Están realizados con materiales de gran calidad (pasta vítrea, pórfidos y mármoles diversos) y desarrollan estructuras arquitectónicas, escenas florales, animalísticas y figuradas, en combinación con placados geométricos. Pérez Olmedo cita entre otras villas las de Malena de Azuara (Zaragoza); Els Munts (Tarragona); Algorós (Alcudia de Elche, Alicante); Los Torrejones de Yecla (Murcia); Carranque (Toledo) y La Vega de Balazote (Albacete), donde se documentaron numerosas piezas marmóreas de reutilización, destinadas a revestimientos parietales (Pérez Olmedo, 1999, 341).

En la inmensa mayoría de los casos constatados, los muros se compartimentan en grandes paneles cuadrangulares con una triple división: zócalo, lienzo de ortostatos y remate, todo ello separado por enmarques más o menos gruesos y elaborados; además es difícil encontrar paredes revestidas solamente con sectilia, ya que éstos forman parte de composiciones mixtas integradas por motivos pictóricos o musivos, pilastras y relieves arquitectónicos (Pérez Olmedo, 1999, 336).

Los primeros sectilia pavimentales se documentan en la península en el siglo I d.C. El número de ejemplos adscritos a época augustea es bastante elevado, fenómeno que afecta, principalmente, a la edilicia pública, pero que no deja de tener reflejo en la privada, donde pavimentos de este tipo suelen constituir el ornato de las estancias principales (oeci y triclinia), aunque no faltan ejemplos en cubicula y letrinas. $\mathrm{Su}$ uso nos ilustra sobre el deseo de las clases dirigentes locales de adoptar los gustos y tendencias de la metrópoli y demostrar así su grado de civilización; por tanto, la difusión de esta técnica pavimental va pareja al avance de la "romanización" (Pérez Olmedo, 1997, 35). A partir del siglo IV d.C. se constata su uso en las villas de gran riqueza, aunque hay también un importante descenso cuantitativo y cualitativo, ya que el número de pavimentos de estas características disminuye en favor de la técnica musivaria. En líneas generales, los pavimentos se conforman mediante unidades modulares que se repiten según el espacio a cubrir, en un diseño general- mente abierto y adaptable a cualquier superficie (Pérez Olmedo, 1999, 336-341).

A lo largo de las diferentes campañas llevadas a cabo en la villa se han recogido numerosos fragmentos de mármol que pasamos a describir a continuación. Siguiendo la tradición de los estudios de materiales romanos que se basan en el término latino marmor, por "mármol" se entienden aquí, además, por supuesto, de los mármoles propiamente dichos, las piedras duras empleadas normalmente en la decoración parietal y pavimental, como las de tipo granítico, porfiroide o alabastroide. Dentro del conjunto de mármoles documentados en El Saucedo podemos distinguir cinco subgrupos atendiendo a sus características morfológicas:

Subgrupo I: mármoles amarillentos rosados, de vetas azuladas y rosadas más o menos intensas, empleados en lastras pavimentales o murales grandes y gruesas.

Subgrupo II: mármoles blancos amarillentos de grano pequeño empleados en lastras finas y quizá en pequeñas tégulas.

Subgrupo III: mármoles blancos amarillentos o cándidos de grano visible empleados en lajas de grosor intermedio, algunas pavimentales o murales y otras tal vez propias de bordes o barandillas.

Subgrupo IV: mármoles blancos muy ligeramente amarillentos o cándidos, con o sin veta, de usos diversos.

Subgrupo V: piedras de gran calidad (importadas).

Subgrupo VI: calizas marmóreas empleadas en columnas y revestimientos pavimentales o murales.

Las piezas marmóreas de la villa talaverana provienen de varias unidades estratigráficas. Nueve de los fragmentos fueron hallados en la unidad superficial, integrada por piedras, cascotes, tejas, etc. Dieciocho de ellos proviene de la unidad 1, correspondiente al derrumbe general y fase de abandono de la villa. Dos más se encontraron en la unidad 2, y otro en la 5. En la unidad 6, un estrato de tierra negra, cenizas, restos de vigas carbonizadas y cascotes del derrumbe correspondiente al incendio del siglo VIII d. C., se encontraron tres de los fragmentos. Dos fragmentos más provienen de la unidad 7. Un fragmento proviene de la unidad 92. Por último, de la unidad 19, un estrato de tierra marrón clara arenosa correspondiente al relleno del derrumbe sobre el mosaico de la estancia octogonal (sudatio) del conjunto termal denominado $\mathrm{B}$, se halló la última de las piezas del conjunto. A este 


\begin{tabular}{|c|c|c|}
\hline CORTE & UNIDAD & $\mathrm{N}^{0}$ INV. DE PIEZA \\
\hline $\mathrm{O} 2$ & U.E. 1 & $25.007 \mathrm{a}$ y b/ $25.001 / 27.008$ \\
\hline $\mathrm{O} 2$ & U.E. 19 & 25.008 \\
\hline M5 & U.E Superficial & $25.010 / 27.000$ \\
\hline M2 & U.E. 2 & $25.015 / 25.016 / 25.020$ \\
\hline $\mathrm{C} 8$ & U.E. 1 & $25.011 / 25.012$ a y c/ 27.007 \\
\hline $\mathrm{C} 4$ & U.E. 7 & $25.021 \mathrm{a} / 25.015$ \\
\hline C10 & U.E. 1 & 25.009 \\
\hline E0 & U.E. 91 & $25.021 \mathrm{~b}$ \\
\hline G1 & U.E. Superficial & 25.002 \\
\hline G1 & U.E. 5 & $25.021 \mathrm{~d}$ \\
\hline G1 & U.E. 6 & $25.021 \mathrm{c}$ \\
\hline G3 & U.E. 1 & 25.003 \\
\hline Q5 & U.E. 5 & 25.022 \\
\hline Q5 & U.E. 6 & $25.021 \mathrm{e}$ \\
\hline Q2 & Desmonte & $25.021 \mathrm{f}$ \\
\hline Q4 & U.E. 1 & $25.004 / 25.005$ \\
\hline Prospección & --------- & 25.021 \\
\hline Limpieza Superficie & --------- & $25.014 / 25.013 / 25.018 / 25.019$ \\
\hline Testigo Acequia & -------- & 25.017 \\
\hline E1 & U.E. 1 & $27.001 / 27.002 / 27.003 / 27.004 / 21.012$ \\
\hline B10 & U.E.Superficial & $27.005 \mathrm{~b}$ \\
\hline $\mathrm{M} 4 / \mathrm{N} 2$ & Perfiles & $27.005 \mathrm{a}$ \\
\hline C9 & U.E.92 & 27.006 \\
\hline $\mathrm{O} 2 / \mathrm{N} 2$ & Testigo & 27.009 \\
\hline $\begin{array}{l}\text { Desmonte de muro } \\
\text { situado sobre mosaico }\end{array}$ & --------- & 27.010 \\
\hline Limpieza Superficial & -------- & 27.011 \\
\hline
\end{tabular}

Distribución de los fragmentos por Cortes y Unidades Estratigráficas.

panorama hay que añadir el hallazgo de tres fragmentos en la prospección, el desmonte, y en un testigo respectivamente.

Se establece así una fecha ante quem del siglo VIII d.C. y podemos señalar, con toda seguridad, que el conjunto de mármoles perteneció originalmente a la decoración pavimental y parietal del edificio bajoimperial (ss. III-IV d.C.), una villa áulica de carácter monumental simple alrededor de peristilo, caracterizada por la multiplicidad de ábsides, la riqueza ornamental, la adopción de un arte oficial y el gusto por las perspectivas interiores. El atrio central estaba rodeado por una galería porticada que daba acceso a las diferentes estancias circundantes y presentaba una fuente monumental adosada al muro noroeste.

Los distintos mármoles presentes en la villa parecen en principio de procedencia local, tal vez del Macizo Hespérico portugués, una de las zonas geográficamente más próximas a El Saucedo de entre las grandes áreas de extracción peninsulares. En las canteras portuguesas se localizan mármoles amarillentos no fétidos, blancos y blancos rosados con venaturas grises (Cisneros, 1988, sobre todo 136 seqq; Gnoli, 1988, 219 y Borghini, 1998, 136-137). Concretamente en la zona de Borba-Estremoz encontramos un mármol de grano grueso y tonalidades blancas, blancas con vetas o manchas grises y amarillentorosáceas. Se trata de un material lapídeo de un alto grado de calidad, que muy probablemente podemos identificar con los blancos amarillentos con venas de color gris azulado y con los rosados de El Saucedo (subgrupo I). Nos encontraríamos así pues ante una variedad clara y otra más intensa de este mármol, que sigue comercializándose hoy en día con el nombre de "Rosa Portugués".

La cronología de la explotación de estas canteras lusitanas se extiende entre el siglo I d.C. y 
el IV d.C. El comienzo de su empleo se remonta a la época augustea, para llegar a alcanzar su fase álgida bajo el reinado de Claudio. Este mármol tuvo un cierta difusión, aunque su comercialización se vio dificultada por la no disponibilidad de una vía fluvial navegable.

Otra zona productora que pudo haber surtido a los constructores de la villa de El Saucedo es el área extremeña, cuna de calizas y brechas que incluyen tonalidades blancas y rojas. No hay que olvidar tampoco la zona de Halconera, cerca de Zafra, donde se extraía un mármol de alto valor ornamental por sus bellas tonalidades violáceas (Rodá, 1998, 113-118). Cabe destacar que entre los mármoles hallados en su día en las excavaciones talaveranas de la Ronda del Cañillo se encuentran blancos de grano grueso, profusamente empleados en época romana y quizá también musulmana. Los autores que se han ocupado de su estudio plantean un origen andaluz o extremeño para estas piedras (Urbina et al. 1997, 285-286), que bien pudieran corresponderse con las de nuestro Subgrupo III, con las que también comparten un uso mayoritario en revestimientos parietales y solados.

Pasando a los materiales importados, que hemos agrupado en el Subgrupo V, hay que comenzar mencionando la presencia en El Saucedo de un fragmento de pórfido verde o serpentino (conocido en la antigüedad como Lapis Lacaedaemonius), que se extraía en la antigua Krokeai (Laconia), según describe Pausanias (3, 21, 4): "Bajando hacia el mar, hacia Gitio, los lacedemonios tienen la aldea de Cróceas, cuya cantera no es una roca continua y [seguida] sino que se extraen piedras semejantes por su forma a las de río y difíciles de trabajar, pero si son trabajadas pueden adornar los santuarios de los dioses, y contribuyen especialmente al embellecimiento de baños y fuentes."

Las canteras fueron localizadas en 1829 por una expedición francesa en la colina de Psephi, sobre la carretera entre las localidades de Alai Bey y Stephania. Estuvieron en uso desde época minoico-micénica hasta la Edad Bizantina y fueron definitivamente destruidas entre la dominación turca y la Segunda Guerra Mundial. Los primeros ejemplos de serpentino en Roma se datan en momentos augusteos. Con Domiciano, las canteras pasaron a ser propiedad imperial. Las características extractivas de la piedra impiden su uso para grandes elementos arquitectónicos; raramente se encuentran pequeños capiteles, columnillas y cornisas, siendo lo normal su uso en opera sectilia. Su difusión geográfica fue enorme y se ha hallado en todo el Imperio (Gnoli, 1988, 141-142; Borghini, 1998, 279-281;
Cisneros, 1988). En Carranque (Toledo) se documentaron algunos fragmentos de este pórfido de Lacedemonia, que formaron parte de pavimentos de opera sectilia: se trata de un triángulo y una loseta cuadrada hallados en 1998 (Rodá, 2001, 111-118).

Por último, cabe resaltar la posibilidad de que dos de los fragmentos marmóreos hallados en El Saucedo correspondan al mármol de origen frigio conocido como pavonazzetto. De las canteras situadas junto al pequeño pueblo turco de Iscehisar (Afyon) se extraía en la Antigüedad este apreciado marmor phrygium, el mármol frigio blanco que a veces se reviste de sutiles veladuras violáceas y otra se cruza con violentas venas de un rojo azulado.

Este mármol frigio se conoció también en época clásica como marmor synnadicum, y aún como marmor docimenium, pues Dokimeion era el nombre antiguo de Iscehisar, mientras Synnada (hoy Subut) correspondía al del lugar desde el que se centralizaba y exportaba la producción. Los marmolistas italianos modernos, por su parte, lo rebautizaron como pavonazzetto por el color de sus vetas (en italiano, pavonazzo significa "pavonado", es decir, azulado o violeta). Como la mayoría de las canteras importantes, las de Afyon fueron de propiedad imperial. Su uso se constata en Roma desde época republicana, pero será en los siglos III-IV d.C. cuando tengan mayor actividad y volumen de exportaciones. El pavonazzetto fue considerado el mármol más caro en el Edicto de Precios promulgado por Diocleciano. Los romanos gustaron de emplearlo con profusión, tanto para elementos arquitectónicos y de revestimiento como para piezas escultóricas, y algunos emperadores, como Heraclio, incluso se hicieron enterrar en sarcófagos labrados en este mármol frigio (Borghini, 1998, 2264-265).

Una vez más, y al igual que en el caso del pórfido verde, el mármol frigio se empleó en la "Basílica" de Carranque, concretamente en la talla de las grandes columnas de fuste liso que delimitaban la nave central, en los fustes y capiteles de lesena que ornaban las paredes interiores, así como en la elaboración de tres fragmentos de pequeñas cornisas molduradas. En algunas de estas piezas pueden leerse las inscripciones DNT y (en griego) EKLIS (Rodá, 2001, 111-113 y Mayer Olivé, 2001, 121-134). Este tipo de mármol se empleó también en la villa de Els Munts (Altafulla, Tarragona), en esta ocasión para la realización de columnas de fuste helicoidal.

Los materiales documentados en el Saucedo son las siguientes: 


\section{SUBGRUPO I}

$\mathbf{N}^{\mathbf{0}}$ Inv. 25.007 a y b.- Conjunto de dos fragmentos de laja cuadrangular de revestimiento pavimental o parietal, uno aproximadamente triangular (25.007a) y otro rectangular (25.007b), con buen pulimento en el anverso, y reverso muy irregular y rastros de lechada a base de carbonatos. El fragmento $25.007 \mathrm{~b}$ presenta en el anverso una línea paralela a un lado largo que marca un ligero cambio de grosor en la superficie, y dos pequeñas muescas rectangulares diagonales a dicha línea. Mármol blanco amarillento de grano fino, con cristales blancos translúcidos muy visibles, y venaturas irregulares de color gris azulado, como el de 25.008 y 25.010. Fetidez: no. Corte O2, UE 1. Dimensiones (desde aquí, siempre en centímetros): (25.007a). Largo máx: 16,2. Ancho máx: 9,6. Grosor máx: 3. Peso (desde aquí siempre en gramos): 1300. Dimensiones: (25.007b): Largo máx: 31,6. Ancho máx: 23,5. Grosor máx: 3,9. Peso: 5455.

$\mathbf{N}^{\mathbf{0}}$ Inv. 25.008.- Fragmento aproximadamente rectangular de laja de revestimiento pavimental o parietal, con anverso bien pulimentado que presenta una ligerísima curvatura, y reverso muy irregular con rastros de lechada a base de carbonatos. Pudo formar parte de un revestimiento parietal. Mármol blanco amarillento de grano fino, con cristales blancos translúcidos muy visibles, y venaturas irregulares de color gris azulado, del mismo tipo que 25.007 y 25.010. Fetidez: no. Corte O2, UE 19 Dimensiones: Largo máx: 9,2. Ancho máx: 5,3. Grosor máx: 2,6. Peso: 230,06.

No Inv. 25.010.- Fragmento aproximadamente triangular con anverso y reverso de pulimento semejante y ligeros rastros en el reverso de lechada a base de carbonatos. Pudo formar parte de un revestimiento parietal. Mármol blanco amarillento de grano fino, con cristales blancos translúcidos muy visibles, y venaturas irregulares de color gris azulado. Fetidez: no. Corte M5, UE superficial. Dimensiones: Largo máx: 6,9. Ancho máx: 4,8. Grosor máx: 1,5. Peso: 80,25.

No Inv. 25013: Fragmento de laja de revestimiento pavimental o parietal, con buen pulimento en anverso y reverso, y rastros de lechada a base de carbonatos en el reverso. Mármol blanco amarillento de grano fino, con cristales blancos translúcidos muy visibles, y venaturas irregulares de color gris azulado. Fetidez: no. UE superficial. Dimensiones: Largo máx: 14,1. Ancho máx: 6,5. Grosor máx: 2,3. Peso: 325.

$\mathbf{N}^{\mathbf{0}}$ Inv. 25014: Fragmento de laja de revestimiento pavimental o parietal con buen pulimento en anverso y reverso, y rastros de lechada a base de carbonatos en el reverso. Mármol blanco amarillento de grano fino, con cristales blancos translúcidos muy visibles, y venaturas irregulares de color gris azulado. Fetidez: no. UE superficial. Dimensiones: Largo máx: 12,2. Ancho máx: 10,3. Grosor máx: 2,1. Peso: 450.

$\mathbf{N}^{\mathrm{o}}$ Inv. 25015: Fragmento de laja de revestimiento pavimental o parietal con buen pulimento en anverso y reverso, y ligeros rastros de lechada a base de carbonatos en los laterales. Mármol blanco amarillento de grano fino, con cristales blancos translúcidos muy visibles, y venaturas irregulares de color gris azulado. Fetidez: no. Corte M2. UE 2. Dimensiones: Largo máx: 12,2. Ancho máx: 8,9. Grosor máx: 3. Peso: 475.

$\mathbf{N}^{\mathbf{0}}$ Inv. 25016: Fragmento de laja de revestimiento pavimental o parietal con buen pulimento en anverso y reverso, y rastros de lechada a base de carbonatos en el reverso. Mármol blanco amarillento de grano fino, con cristales blancos translúcidos muy visibles, y venaturas irregulares de color gris azulado. Fetidez: no. Corte M2. UE 2. Dimensiones: Largo máx: 12,6. Ancho máx: 10,9. Grosor máx: 3,2. Peso: 675.

$\mathbf{N}^{\circ}$ Inv. 25017: Fragmento de laja de revestimiento pavimental o parietal con excelente pulimento en anverso y reverso, y rastros de lechada a base de carbonatos en el reverso. Mármol amarillento crema de grano fino con la práctica totalidad de la superficie ocupada por una mancha de color rosado intenso y uniforme. Fetidez: no. UE testigo acequia. Dimensiones: Largo máx: 23,4. Ancho máx: 9,6. Grosor máx: 3,6. Peso: 1275.

$\mathbf{N}^{\mathbf{0}}$ Inv. 25018: Fragmento de laja de revestimiento pavimental o parietal con buen pulimento en anverso y reverso, y rastros de lechada a base de carbonatos en el reverso. Mármol de color rosado amarillento uniforme, de grano fino. Fetidez: no. UE superficial. Dimensiones: Largo máx: 10,8. Ancho máx: 3,3. Grosor máx: 2,9. Peso: 232,27.

\section{SUBGRUPO II}

$N^{o}$ Inv. 25001.- Pieza redondeada, aproximadamente hemiesférica por uno de sus lados y plana por el otro, en el que presenta una protuberancia descentrada en forma de pirámide truncada. El aspecto general es el de una especie de clavo pétreo, quizá empleado en decoración parietal -se ofrece otra hipótesis sobre esta pieza en el comentario dedicado a los fragmentos escultóricos. El anverso aparece muy irregular, por falta de acabado y/o erosión. Se aprecian varias hendiduras cruzadas por otra más larga en la zona central. El reverso conserva huellas de lechada compuesta por carbonatos. Mármol blanco ligerísimamente amarillento, de grano muy 
fino, compacto y homogéneo. Fetidez: no. Corte O2, UE 1. Dimensiones: Diámetro: 8. Grosor máximo sin contar con la protuberancia trasera: 1,9; incluida la protuberancia: 4,1. Protuberancia: altura sobre la hemiesfera: 1,1 ; medidas máximas de la sección cuadrangular: 3,6 x 3,6. Peso: 264,10.

$\mathbf{N}^{o}$ Inv. 25019: pequeño fragmento cuadrangular con una cara lisa y bien pulimentada y otra ligeramente convexa, también con buen pulimento. Mármol blanco ligerísimamente amarillento, de grano muy fino, compacto y homogéneo. Fetidez: no. UE superficial. Dimensiones: Largo máx: 4,2. Ancho máx: 2,5. Grosor máx: 1. Peso: 25,81.

$\mathbf{N}^{\circ}$ Inv. 25020: pequeño fragmento cuadrangular, con una cara muy irregular (probablemente rota) con restos de lechada de carbonatos, y otra lisa con excelente pulimento. Mármol blanco ligerísimamente amarillento, de grano muy fino, compacto y homogéneo. Fetidez: no. Corte M2. UE 2. Dimensiones: Largo máx: 4. Ancho máx: 3,5. Grosor máx: 3,2. Peso: 85,13.

$\mathbf{N}^{o}$ Inv. 25.011.- Fragmento aproximadamente rectangular con una especie de baquetón lateral de sección semicircular peraltada en uno de los lados largos. El anverso está pulido sin demasiado esmero y presenta rastros de lechada a base de carbonatos; el reverso es irregular y está posiblemente fragmentado. El aspecto general recuerda a una pequeña tégula. Mármol blanco amarillento de grano fino, del mismo tipo que 25.005 y 25.012 a y b, que presenta además unas ligerísimas sombras rojizas y violáceas sólo visibles en el reverso. Fetidez: no. Corte C8, UE 1. Dimensiones: Largo máx: 9,3. Ancho máx: 4,1. Grosor máx: 1,6; medio del baquetón: 1. Peso: 128,44 .

No Inv. 25012.- Conjunto de cinco fragmentos, de los cuales dos de ellos, uno aproximadamente rectangular (25.012a) y otro poligonal (25.01b) pertenecen a grandes lajas pavimentales o parietales. Los otros tres, dos aproximadamente triangulares $(25.012 \mathrm{c} \mathrm{y} \mathrm{d})$ y uno cuadrangular (25.012e), pudieron también formar parte de revestimientos murales. Todas las piezas presentan pulimento semejante en anverso y reverso y restos de lechada a base de carbonatos en el reverso. Los fragmentos 25.012a y b son de mármol blanco amarillento de grano fino, del mismo tipo que 25.005 y 25.011. El fragmento 25.012a presenta una ligerísima sombra violácea. El fragmento $25.012 \mathrm{c}$, d y e son de mármol blanco cándido de grano grueso, con cristales muy visibles. Corte C8, UE 1. Fetidez: no. Dimensiones de los diversos fragmentos: (25.012a): Largo máx: 15,2.
Ancho máx: 8,7. Grosor máx: 1,7.Peso (25.012a): 432,8; Peso: 128,44 (25.012b): Largo máx: 24,4. Ancho máx: 21,5. Grosor máx: 1,4. Peso: 679,5; (25.012c): Largo máx: 6,7. Ancho máx: 4,8. Grosor máx: 2,1. Peso:104,36; (25.012d) Largo máx: 7,4. Ancho máx: 3,8.Grosor máx: 1,9. Peso 73,20; (25.012e). Largo máx: 6,85. Ancho máx: 5,2. Grosor máx: 2,1. Peso: 139,78.

$\mathbf{N}^{0}$ Inv. 25.005.- Fragmento aproximadamente cuadrangular con una especie de baquetón lateral de sección semicircular peraltada similar el del fragmento 25.011 en uno de los lados cortos. Anverso de pulimento mediocre; el reverso es irregular y presenta rastros de lechada a base de carbonatos. El aspecto general recuerda a una pequeña tegula. Mármol blanco amarillento de grano fino, del mismo tipo que 25.011 y 25.012 a y b. Fetidez: no. Corte Q4 UE1.Dimensiones: Largo máx: 9. Ancho máx: 7. Grosor máx: 1,4; medio del baquetón: 1. Peso: 125,06.

$\mathbf{N}^{o}$ Inv. 25021a.- Fragmento aproximadamente rectangular, de anverso y reverso ligeramente convexos y cóncavos respectivamente. Buen pulimento. Restos de lechada en el anverso. Mármol blanco amarillento de grano fino. Fetidez: no. Corte C-4, UE 7. Dimensiones: Largo máx: 6,0. Ancho máx: 3,4. Grosor máx: 3,1. Peso: 82,42 .

\section{SUBGRUPO III}

$\mathbf{N}^{\mathrm{o}}$ Inv. 25.004.- Fragmento aproximadamente rectangular, de anverso y reverso pulimentados sin apenas diferencia. Rastros de lechada compuesta por carbonatos solamente en el perfil. Pudo quizá formar parte de algún elemento realizado con piezas unidas entre sí, pero que no constituían un revestimiento (por ejemplo un pequeño borde o barandilla). Mármol blanco amarillento de grano muy fino, compacto $y$ homogéneo, como el de 25.009. Fetidez: no. Corte Q4, UE 1. Dimensiones: Largo máx: 8. Ancho máx: 2,8. Grosor máx: 1,5. Peso: 60,57.

$\mathbf{N}^{\circ}$ Inv. 25.009.- Fragmento aproximadamente triangular de anverso y reverso pulimentados sin apenas diferencia. El reverso presenta huellas de lechada a base de carbonatos. Pudo formar parte de un revestimiento parietal. Mármol blanco amarillento de grano muy fino, compacto y homogéneo del mismo tipo que 25.004, pero con una zona de coloración rojizorosada muy intensa uno de sus ángulos, debida a la presencia de hematites. Fetidez: no. Corte C10, UE 1. Dimensiones: Largo máx: 12,2. Ancho máx: 10,6. Grosor máx: 2. Peso: 245

$\mathbf{N}^{\mathrm{o}}$ Inv.25021: Fragmento de laja con buen pulimento en anverso y reverso, y rastros de 
lechada a base de carbonatos en el reverso. Pudo formar parte de un revestimiento parietal. Mármol blanco cándido de grano grueso. Fetidez: no. UE prospección. Dimensiones: Largo máx: 13,1. Ancho máx: 8,0. Grosor máx: 1,7. Peso: 325.

$\mathbf{N}^{\mathbf{0}}$ Inv. 25.021b.- Fragmento de laja con buen pulimento en anverso y reverso, y rastros de lechada a base de carbonatos en el reverso. Pudo formar parte de un revestimiento pavimental. Mármol blanco cándido de grano grueso. Fetidez: no. Corte E0, UE 91. Dimensiones: Largo máx: 7,9. Ancho máx: 7,7. Grosor máx: 2,4. Peso: 248,75.

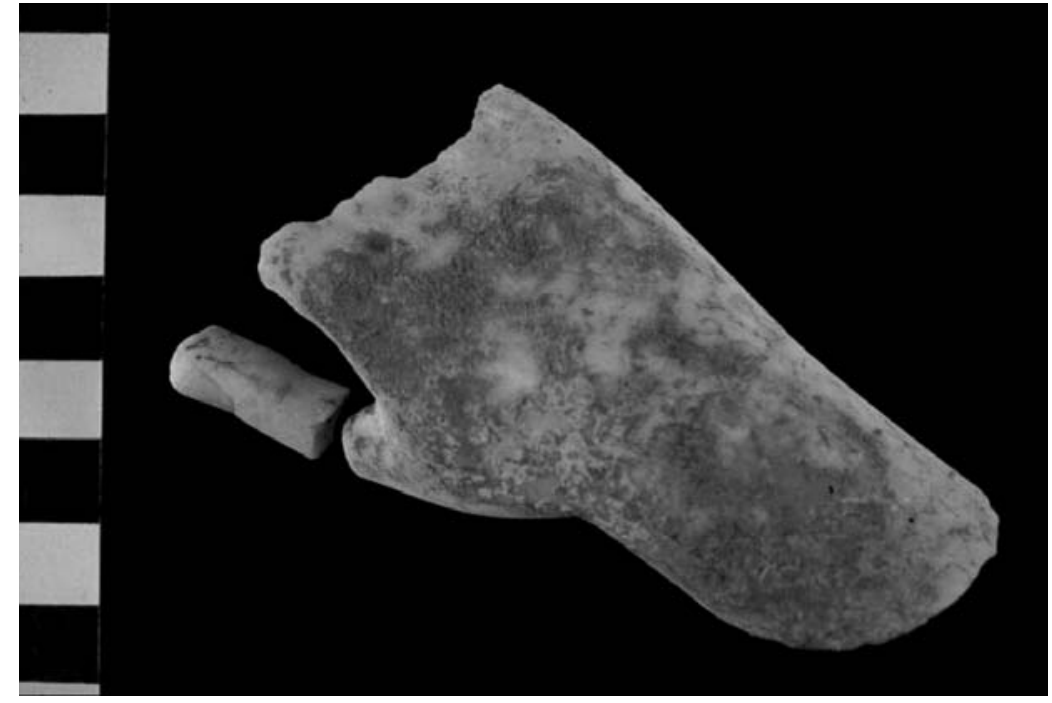

2.1. Foto de la mano derecha y dedo pulgar ( $N^{0}$ Inv.27.005)

\section{SubGrupo IV}

$\mathbf{N}^{\mathbf{0}}$ Inv. 25002.- Fragmento aproximadamente cuadrangular de anverso pulimentado y reverso fracturado y muy irregular. No hay rastros de lechada. Pudo formar parte de un opus sectile. Mármol blanco cándido, de grano muy fino, compacto y homogéneo, con venaturas y manchas que van del rojo oscuro y marrón casi negro al anaranjado claro, visibles sólo en el anverso. Fetidez: no. Corte G1, UE: superficial. Dimensiones: Largo máx: 5. Ancho máx: 3,9. Grosor máx: 2,4. Peso: 66,06.

\section{SUbGRUPO V}

$\mathbf{N}^{o}$ Inv. 25.006.- Fragmento cuadrangular, de pulimento extremadamente fino, sin diferencia entre anverso y reverso. Pórfido verde de Grecia (a veces llamado serpentino siguiendo a los marmolistas romanos modernos), de fondo verde intenso y manchitas irregulares de color verde claro en forma de pequeños trazos más o menos rectangulares que muchas veces se cruzan. El fragmento presenta inclusiones de cristales azulados. No hay rastros de lechada. Es posible que no llegara a utilizarse en su destino habitual de parte de un sectile. Corte: R3, UE: $6 \mathrm{~F}$ Dimensiones: Largo máx: 7,6. Ancho máx: 7,2. Grosor máx: 1,3. Peso: 151,94 (Figura $n^{0} 2.1$ )

No Inv. 25.021c.- Fragmento aproximadamente triangular, de pulimento fino y cristales excepcionalmente brillantes. Anverso y reverso pulidos. Fondo blanco-crema translúcido, con vetas y óculos de color azulado-violáceo. Es posible que se trate de pavonazzetto de Frigia. Corte: G1, UE: 6. Dimensiones: Largo máx: 11,8. Ancho máx: 7,0. Grosor máx: 2,2. Peso: 230,49.

No Inv. 25.021d.- Fragmento aproximada- mente cuadrado. Anverso pulido; reverso partido e irregular. El material es idéntico al de la pieza anterior; aunque han sido hallados en estratos distintos, ambos fragmentos formaron parte del mismo enlosado o revestimiento parietal. Corte: G1, UE: 5. Dimensiones: Largo máx: 4,6. Ancho máx: 3,7. Grosor máx: 2,2. Peso: 39,33 .

\section{SUbGRUPO VI}

No Inv. 25021e.- Fragmento desprendido de un de fuste de columna dejado in situ en el yacimiento. Exterior pulido, interior partido e irregular. Caliza marmórea gris azulada con cristales gruesos y brillantes, común en la zona. Fetidez: no. Corte Q5, UE 6. Dimensiones: Largo máx: 10,1. Ancho máx: 8,1. Diámetro máx. aprox. del fuste a la altura del fragmento: 21. Peso: 225,13.

$\mathbf{N}^{\mathrm{o}}$ Inv. 25015.- Escama de caliza marmórea gris azulada idéntica a la del fragmento anterior. Fetidez: no. Corte C-4, UE 7. Dimensiones: Largo máx: 3,8,1. Ancho máx: 2,5. Grosor máx: 0,8. Peso: 11,62 .

$\mathbf{N}^{\mathbf{0}}$ Inv. 25003.- Fragmento extremadamente deteriorado de moldura redondeada, que posiblemente pertenecía a una basa de columna. El exterior es gris uniforme y opaco; el interior presenta cristales muy gruesos, de color blanco transparente y gris azulado y fragilidad extrema, con abundancia de grietas y continua descamación. Es más que probable que la pieza haya sufrido el fenómeno conocido como reducción de sección (por efecto de un calor intenso, las piedras de composición caliza se desmigajan), y que originalmente estuviera labrada en la misma caliza marmórea gris azulada de los fragmentos anteriores. En la zona de proveniencia de la villa 
están documentados niveles de incendio. Fetidez: no. Corte G3, UE 1. Dimensiones: Largo máx: 14,3. Ancho máx: 7,1. Diámetro máx. aprox. de la basa original: 30. Peso: 650 .

$\mathbf{N}^{\mathbf{0}}$ Inv. 25021f.- Fragmento aproximadamente triangular, con buen pulimento en anverso y reverso muy irregular. Caliza marmórea blanquiazulada de grano fino. Fetidez: no. Corte Q2, desmonte E195. Dimensiones: Largo máx: 8,1. Ancho máx: 8,0. Grosor máx: 1,6. Peso: 120,74.

$\mathbf{N}^{\circ}$ Inv. 25022- Columna de caliza marmórea gris azulada con cristales gruesos y brillantes común en la zona. Compuesta por basamento de $17 \mathrm{~cm}$. de diámetro y $4 \mathrm{~cm}$., de alto; fuste de 114 '5 cm. de alto, presenta un diámetro mayor en el centro, alcanzando los 16'8 cm.; capitel integrado por collarino y ábaco de $3,5 \mathrm{~cm}$. de alto y $15 \mathrm{~cm}$. de diámetro. Corte Q5 UE5.

$\mathbf{N}^{\mathbf{0}}$ Inv. 25023.- Columna completa. Se conserva: el plinto de $21 \mathrm{~cm}$., de alto y unas medidas externas de 47 x 44 x 46 x 45 cm.; y unas medidas internas de 41 × 42 × 42 × $41 \mathrm{~cm}$; el basamento, compuesto por varias molduras y una altura de 17' $5 \mathrm{~cm}$.; y $41 \mathrm{~cm}$. de lado; el fuste está partido en tres partes: el primer fragmento tiene $88 \mathrm{~cm}$. de alto; con un diámetro inferior de 32 cm.; y superior de 30'5 cm.; rematado en una moldura de $6 \mathrm{~cm}$.; el segundo fragmento tiene $92 ' 5 \mathrm{~cm}$. de altura; diámetro inferior de $32 \mathrm{~cm}$; y superior de $30 \mathrm{~cm}$., rematado en una moldura de 6 ' $5 \mathrm{~cm}$.; el tercer fragmento, correspondiente a la parte central de la columna tiene $63 \mathrm{~cm}$. de alto.

\section{II.2.- Las piezas escultóricas.}

Los primeros descubrimientos se remontan al siglo XVI, cuando se conocen noticias sobre hallazgos arqueológicos en toda la zona; especialmente monedas, cerámicas, esculturas y fragmentos de mármoles. Entre los hallazgos más significativos está el referido a un ara dedicada a las ninfas, dada a conocer por J. Cornide en 1796, aunque hallada y descrita por el fraile jerónimo Ajofrín del convento talaverano de Santa Catalina (Canto, 2001,113-117).

Fidel Fita, con ocasión de una excursión al lugar proporcionó detalles precisos acerca del yacimiento destacando la localización de pendientes de oro, busto marmóreo de medio cuerpo que figuraba a un varón togado, sepulturas con sus cadáveres, molduras de mármol y monedas muchas de cobre, la mayor parte del Bajo imperio. El citado autor realizó una extensa descripción del togado y cuenta como acabó convertido en Santa Catalina y apedreado durante la desamortización eclesiástica "Este togado, según he leído ya en Gómez de Tejada era en el siglo XVI muy famoso en Talavera, donde le llamaban el Catón (por el padre A. Soto puede completarse que tenía cabello y barba cortos). Al describirlo, Ajofrín, recuerda que tenía una pareja femenina llamada La Catona (Canto, 2001).

A través de Martín Aguado conocemos que a principios del siglo XX se recogieron dos fustes $\mathrm{y}$ una basa o capitel de otras tantas columnas que se llevaron a la vivienda del entonces dueño de la finca, en el Casar de Talavera. Los fustes se emplearon para la construcción de una pared; la basa o capitel, como losa en la pavimentación del patio (Martín Aguado, 1965, s.p).

Antes de que El Saucedo fuera reconvertido en terreno de regadío, era según describe Martín Aguado "un terreno de secano, plagado de piedras y cascotes, en el que podían reconocerse, vagamente, las ruinas de un antiguo poblado. Ruinas que la gente aprovechaba como cantera al edificar sus casas, y en las que aparecían, de vez en cuando, columnas de mármol, mosaicos, viejas monedas y otros mil objetos desusados" (Martín Aguado, 19, s.p,)

Martín Aguado, en la década de los sesenta, interesado por los descubrimientos que se habían realizado en 1959, con motivo de la construcción de un pozo y una casa de labor por parte de D. Eugenio Manzano, realizó una primera visita al lugar constatando construcciones arquitectónicas, además de elementos de cultura material, entre los que destacan "elementos constructivos en mármol como por ejemplo otra basa o capitel de columna, una pileta (mortero o aguamanil) de la que se conservan dos trozos; una placa que tenía grabada la figura de un pez y un fragmento de estatua" (Martín Aguado, 1965, s.p.).

Estos primeros hallazgos se completan con la documentación de una plaqueta de mármol blanco que estuvo enclavada en la estancia interpretada como Apodyterium/frigidarium. La plaqueta fue descrita por Ramos Sainz en los siguientes términos: "tiene $49 \mathrm{~cm}$. de largo por $50 \mathrm{~cm}$. de ancho y 7'50 cm. de grosor, presenta en su decoración una roseta hexapétala inscrita en un círculo, cada uno de sus pétalos tiene tres incisiones rectilíneas y el umbo sobresale en relieve con un orificio en el centro. El círculo, con un hexágono curvilíneo interno va rodeado de una moldura doble sogueado; los ángulos externos de aquel se decoran con diversos elementos, en dos de ellos se disponen cuatro molduras longitudinales, en otro una trifolia, y en el cuarto cuatro pequeñas volutas" (Ramos, 1995, 106-107).

Los mármoles empleados para la elaboración de las esculturas es el mismo que el utilizado para 
la elaboración de las lastras pavimentales y/o parietales, pero el número de piezas escultóricas que hemos exhumado es escaso. Por este motivo el estudio que podemos hacer sobre estas piezas es restringido porque al no conservar restos suficientes es imposible reconstruir un aspecto aproximado de cómo decorarían las esculturas los diferentes ámbitos de la villa de El Saucedo.

Pero esta limitación es generalizada. El estudio de la escultura en el territorio lusitano relacionada con las villae presenta varios problemas: en primer lugar, los hallazgos obedecen a causas fortuitas, generalmente excavaciones de urgencia, realizadas en frecuentes ocasiones, con el único fin de recuperar piezas. Son escasas las obras que han aparecido en una excavación sistemática y que no plantean dudas de localización.

También encontramos piezas descontextualizadas que, a tenor de sus rasgos morfológicos, intuimos que pueden proceden de villae. Con ellas sólo cabe elaborar hipótesis de trabajo en relación al tema tratado.

Otra asignatura pendiente para acometer el estudio de la plástica estriba en la ausencia de análisis de material marmóreo que se relaciona con las villae, cuestión que podría esclarecer aspectos de sumo interés, tales como la procedencia de la obra, su conexión con talleres locales o foráneos, así como la predilección por un tipo u otro de materia prima escultórica.

Con este panorama es difícil trazar la evolución de la escultura adscrita a este amplio territorio. A diferencia de otras áreas peninsulares, como la Bética o la Tarraconense, en donde los hallazgos permiten establecer una aproximación al problema en el territorio lusitano. Sería conveniente poder, en el futuro, contar con recopilaciones de conjunto al modo de las efectuadas en Italia.

Después de realizar una recopilación bibliográfica sobre los estudios escultóricos de las villae, podemos llegar a interesantes resultados que se pueden materializar en las piezas que proceden del El Saucedo y que más adelante analizaremos. En primer lugar, todos los investigadores han establecido el predominio de la estatuaria menor ornamental, que mantiene idénticos ciclos decorativos en toda la Península Ibérica, aunque no es factible determinar la preferencia por temas concretos. También se ha observado la presencia de variedad estatuaria: divinidades, retratos, etc.

Es importante resaltar que en la antigüedad, la mayor parte de las estatuas procedentes del ámbito privado eran mármol blanco (como los fragmentos que hemos hallado en El Saucedo). A pesar de que en general no contamos con un estudio mineralógico, se ha podido constatar que dicho material procede principalmente de Italia y Grecia, aunque también tenemos noticias de algunas canteras locales en la Península Ibérica.

En cuanto al tamaño de las esculturas la mayoría, independientemente del material, es de pequeñas dimensiones no sobrepasando en general el formato de estatuilla.

En lo que respecta a la temática, la gran mayoría de las esculturas procedentes del ámbito privado representan a divinidades. Existen imágenes de casi todos los dioses del panteón romano como, por ejemplo, Saturno, Apolo, Mercurio, Asclepios, Eros, Minerva, Diana, Venus e Hygiea. Obviamente son asimismo habituales aquellas relacionadas con la naturaleza y con la fertilidad o divinidades acuáticas. Estas figuras de divinidades se presentan casi siempre aisladas, si bien, esporádicamente, se muestran reunidas en grupos de contenido mitológico. También, en las villae de la antigua Hispania se hallaban expuestos retratos imágenes de la familia imperial, efigies de personajes desconocidos, etc.

En cuanto a la cronología de las esculturas procedentes de las villae, la mayor parte pueden ser datadas a finales del siglo I y en el II d.C., perteneciendo muchas de ellas al periodo de los Antoninos. A comienzos de la tercera centuria cesa casi abruptamente la producción escultórica, lo que está relacionado con la crisis militar, política y económica que sacude al Imperio. A pesar de la recuperación a todos los niveles que experimenta el mundo romano a finales del siglo III y a lo largo del IV, y al contrario de lo que sucede con la pintura y el mosaico, en Hispania no se constata la existencia de talleres de plástica exenta, por lo que en las villae de este periodo se reutilizan las estatuas de épocas anteriores. Debido a ello, la información que poseemos sobre los programas ornamentales en determinados espacios de la pars urbana de una villa, generalmente se refiere al Bajo Imperio, aunque podemos suponer que también refleja la decoración escultórica de esa villa en los primeros siglos de nuestra era. De todas formas nuestros conocimientos a este respecto son muy parciales, ya que son muy pocas las villae en Hispania en las que se ha recuperado más de una escultura.

Centrándonos en el estudio escultórico de la villa de El Saucedo, y como hemos comentado anteriormente, podemos observar que los restos que poseemos son escasos, para hacernos una idea del repertorio de esculturas que adornarían nuestra villa. Podemos deducir que estas piezas 
de mármol se utilizaron fundamentalmente para la decoración y monumentalización de los ambientes domésticos de la casa, centrándose su uso en torno al peristilo, así como desde un punto de vista funcional en la decoración arquitectónica (revestimientos parietales y de pavimentos, fustes de columnas...), y en la escultórica. Las piezas escultóricas que forman el catálogo son las siguientes:

\section{SubGruPo I:}

$\mathbf{N}^{\mathbf{0}}$ Inv. 27.000.- Fragmento cilíndrico de mármol blanco cándido de grano fino; huellas de lechada en un lateral. Corte: M5; U.E.Superficial; Dimensiones: Largo máx: 4َ5, Ancho máx: 2`1, Grosor: 2־2.

$\mathbf{N}^{\mathbf{0}}$ Inv. 27.001a.- Pieza escultórica con partes de drapeados y molduraciones; mármol blanco cándido virando al azulado, de grano fino semejante al de la pieza 27.000. Corte E0; U.E.1; Dimensiones: Largo máx: 15; Ancho máx: 115; Grosor: 3,3.

$\mathbf{N}^{\mathbf{0}}$ Inv.27.002b.- Pieza escultórica con partes de drapeados y molduraciones; mármol blanco cándido virando al azulado, de grano fino semejante al de la pieza 27.000. Corte E1; U.E.1; Dimensiones: Largo máx: 11; Ancho máx: 11; Grosor:3־3.

$\mathbf{N}^{\mathbf{0}}$ Inv.27.003c.- Pieza escultórica con partes de drapeados y molduraciones; mármol blanco cándido virando al azulado, de grano fino semejante al de la pieza 27.000. Corte E1; U.E.1; Dimensiones: Largo máx: 145; Ancho máx: 10; Grosor: 8־3.

No Inv. 27.004d.- Pieza escultórica con partes de drapeados y molduraciones; mármol blanco cándido virando al azulado, de grano fino semejante al de la pieza 27.000. Corte E1; U.E.1; Dimensiones: Largo máx: 9; Ancho máx: 85; Grosor: 344 .

No Inv. 27.012.- Fragmento de mármol blanco amarillento de grano muy grueso; cara posterior irregular. En la cara anterior con restos de lechada plano, se lee en dos líneas XII/ P. Corte E1, U.E.1. Dimensiones: Largo máx: 8־7 Ancho máx: 4; Grosor: 3־7 Altura de las letras: 3,8 cm.

\section{SUbGRUPO II:}

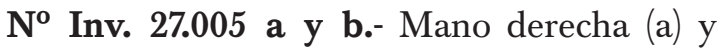
dedo pulgar (b): mármol blanco cándido de grano muy fino; huellas de lechada a base de carbonatos en el dorso de la mano. 27.005 (a): Corte M4/N2; Perfiles. Dimensiones: Largo máx: 8־3; Ancho máx: 4־3; Grosor:311/ 27.005(b): Corte B10, U.E. Superficial. (Fig. 2.1).
No Inv. 27.006.- Mano izquierda con fragmento de arco: mármol blanco cándido de grano muy fino. Corte C9; U.E. 92. Dimensiones: Largo máx: 13`5; Ancho máx: 6,1; Grosor: 2־․

$N^{o}$ Inv. 27.007.- Antebrazo izquierdo que corresponde a la pieza anterior (27.006).Es de mármol blanco cándido de grano muy fino. Corte C8, U.E.1. Dimensiones: Largo máx: 175; Ancho máx: 7־5; Grosor: 4־2.

$\mathbf{N}^{\mathbf{0}}$ Inv. 27.008.- Fragmento de mármol en forma de hemiesfera. Podría ser la parte superior de una cabeza, las incisiones responderían a la tosca representación de un peinado con raya central. Este fragmento esta recogido en el apartado de los placas marmóreas pariétales y pavimentales con el No Inv. 25.001. Corte O2, UE 1. Dimensiones: Diámetro: 8. Grosor máximo sin contar con la protuberancia trasera: 1,9; incluida la protuberancia: 4,1. Protuberancia: altura sobre la hemiesfera: 1,1; medidas máximas de la sección cuadrangular: 3,6 x 3,6.

$\mathbf{N}^{o}$ Inv. 27.013.- Pequeño fragmento cuadrangular con una cara lisa y muy bien pulimentada y otra ligeramente convexa, también con buen pulimento.

$\mathbf{N}^{0}$ Inv. 27.014.- Pequeño fragmento cuadrangular, con una cara muy irregular, y otra con excelente pulimento.

$\mathbf{N}^{\mathbf{0}}$ Inv. 27.009.- Fragmento de pliegues de vestidura: mármol blanco amarillento de grano fino. Huellas de coloración debido al contacto con un objeto de hierro en un lateral. Restos de lechada en el reverso.

$\mathbf{N}^{\mathbf{0}}$ Inv. 27.010.- Fragmento de piernas: mármol blanco amarillento de grano fino, presenta rastros de coloración de origen metálico debido al contacto con un vástago de hierro y a un objeto indeterminado de cobre en el orificio presente en la zona central de la pieza y a otro vástago de hierro en un orificio lateral. Fue hallado en durante el desmonte del muro que estaba sobre el mosaico. Dimensiones: Largo máx: 105; Ancho máx: 19; Grosor: 5־5.

$\mathbf{N}^{\mathbf{0}}$ Inv. 27.011.- Fragmento plano con relieve vegetal, tal vez una hoja de acanto. Mármol blanco amarillento de grano fino. Testigo O2/N2. Dimensiones: Largo máx: 115; Ancho máx: 85; Grosor: 422.

Para poder hacer un estudio estilístico de estas piezas nos encontramos con dos problemas: por un lado, el mal estado de conservación de gran parte del material, que nos impide apreciar muchos detalles de la labra y el acabado; y la fragmentariedad de un número importante de piezas dificulta también la identificación del tipo escultórico al que pertenece. 


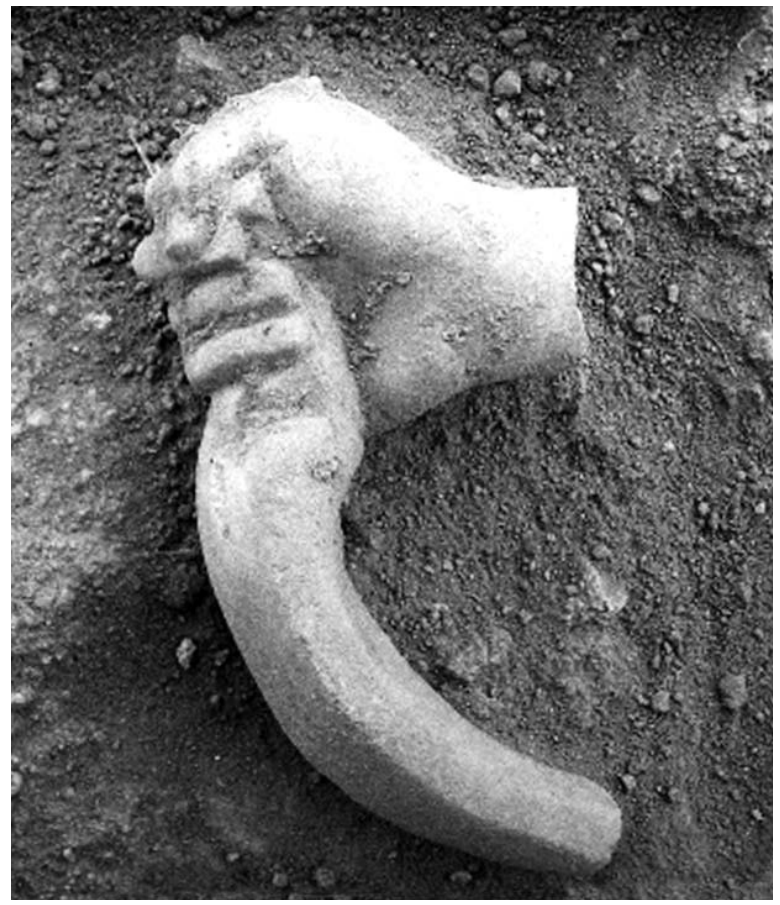

2.2. Foto de la mano izquierda con un fragmento de arco

( ${ }^{\circ}$ Inv. 27.006)

El hallazgo que nos puede aportar su identidad es el fragmento de la mano tendiendo un arco (Fig.2.2), y su antebrazo. Esta pieza es de la misma factura que la mano hallada en la campaña anterior ( $\mathrm{N}^{\mathrm{o}}$ Inv.27.005 a y b), pudiéndose tratar de un Eros en mármol blanco. Tenemos un ejemplo parecido en la villa del Carrascal (Talavera la Real), donde se exhumó la cabeza de esta divinidad. Es una representación muy conocida en los contextos domésticos. En general existe una cierta predilección por las representaciones de deidades en las villae, esta tendencia no es algo regional sino que corresponde con lo que es usual en todo el mundo romano (Koppel, 1993, 227). Se decoraban preferentemente aquellos espacios que podía y debían ser vistos, como, por ejemplo, las estancias de recepción, los peristilos, los jardines y en éstos las fuentes y ninfeos. Un lugar especial lo ocupan los edificios termales en cuyas salas, principalmente los frigidaria, también se colocaban esculturas.

La escultura en las villae, aún cuando en su mayor parte representan a divinidades, no era objeto de culto religioso. Su función era de envolver a sus habitantes en un ambiente de connotaciones sagradas y trasmitir la imagen de una vida ociosa alejada de lo cotidiano. Al mismo tiempo la escultura servía para documentar el interés de los propietarios por el mito y la cultura griega y mostrar también su poder económico y posición social.
El estudio de R. Neudecker (1988) sobre la decoración escultórica en las villae de Italia, ha demostrado que las figuras de musas o de retratos de hombres ilustres griegos aparecen casi exclusivamente en las grandes mansiones de la alta aristocracia romana, mientras que es extraño encontrar estas imágenes en las domus y villae de las personas que no pertenecieran a este reducido estrato social.

La piezas que corresponden con el número de inventariado del 27001 al 27004, nos permiten plantear la hipótesis de identificarlas con fragmentos de vestiduras de una estatua, más o menos de tamaño natural. Es una apreciación muy subjetiva, pero analizando otros estudios como el de I. M. López López (1998, 99-102) donde se recoge en un catálogo las estatuas masculinas togadas y las femeninas vestidas, las figuras que aparecen con el número $74 \mathrm{~B}, 75 \mathrm{~A}, 78 \mathrm{C}$ y $79 \mathrm{~A}$ son similares a nuestros fragmentos. La autora los clasifica en un anexo como indeterminadas pero posiblemente formasen parte de una vestimenta. Si esta hipótesis fuese válida podemos declarar que en nuestra villa talaverana existió diferentes estatuas que decoraban majestuosamente los pasillos y ambientes. Esperamos que en futuras campañas de excavación salgan a la luz fragmentos más esclarecedores que nos permitan la identificación de las estatuas.

Sobre la cronología de nuestros hallazgos marmóreos, hemos de remitirnos a los paralelos de otras villas hispanas, ya que en nuestro yacimiento han aparecido en diferentes niveles (incluso a nivel superficial), y por tanto resultaría difícil dar una fecha precisa. También se le debe sumar la circunstancia de que la villa fue ocupada de forma continuada durante varios siglos, produciéndose seguramente una cambio en la decoración de la misma. Gracias a nuestros trabajos de excavación sabemos que la villa sufrió transformaciones a partir del siglo V d.C., y la pars urbana de la villa bajoimperial, concretamente el peristilo, Oews, y habitaciones adyacentes se abandonaron y cambiaron su funcionalidad, convirtiéndose en lugares de almacén y zona de producción. Esta transformación se debió a la construcción de una basílica cristiana, por tanto encontramos un cambio de propietario, del domini romano al nuevo poder emergente la Iglesia cristiana. La nueva funcionalidad del lugar no tenía cabida para los adornos paganos, por tanto todo elemento decorativo fue reutilizado para las nuevas necesidades o destruido.

Dentro de este apartado de las piezas escultóricas se ha documentado el uso del alabastro para la talla de un recipiente. En nuestro catálogo estos fragmentos los tenemos clasificados con 
estos números:

$\mathbf{N}^{\mathbf{o}}$ Inv. 28.000.- Fragmento de vaso realizado en alabastro blanco de veladuras ligeramente amarillentas. Corte C10; U.E.1 (perfil). Dimensiones: Largo máx: 3; Ancho máx: 5; Grosor: 1'1.

$\mathbf{N}^{\text {o }}$ Inv 28.001 a y b- Dos fragmentos de un vaso realizado en alabastro blanco de veladuras ligeramente amarillentas. Corte C9; U.E.92. Dimensiones: Largo máx: 7¹; Ancho máx: 15; Grosor: 1¹.

En cuanto a este material pétreo debemos señalar que el alabastro, delicado y translúcido, fue utilizado en el Mundo Antiguo desde momentos muy tempranos. La apariencia marmórea, la ductilidad y la traslucidez le convirtieron en un mineral muy apreciado por sus valores ornamentales. Fácil de trabajar, permite al mismo tiempo labrar detalles minuciosos, y revela mediante el pulimento unas características estéticas altamente apreciadas. Por otra parte, se trata de una roca fácilmente erosionable a la intemperie, por lo que su empleo se restringe a elementos interiores ${ }^{2}$. Hay dos tipos fundamentales de alabastro: uno está compuesto por sulfato de calcio, y el otro por carbonato cálcico (este último es el alabastro oriental, a veces mal llamado ónice u onix). Como decíamos, se trata de una roca frágil y relativamente blanda, con sólo 2,5 de dureza en la escala de Moss. La estructura interna está formada por cristales prismáticos alargados. Por lo general, el alabastro pesa entre 2200 y 3000 kilos por metro cúbico, dependiendo de su contenido de agua. Las técnicas de talla del alabastro son similares a las de otras piedras duras, con la lógica adaptación particular de los materiales e instrumentos a la fragilidad de la roca alabastrina.

La fase final del trabajo del alabastro, el pulimento, es la que confiere a la piedra sus rasgos estéticos distintivos. La artesanía tradicional del alabastro en Europa ha empleado hasta hace no tantos años pieles de animales (normalmente de tiburón) y elementos vegetales húmedos para comenzar a pulir la piedra. Tras esta primera fase de pulimento, se aplicaba una pasta de jabón y cenizas de huesos de bóvido. A continuación se frotaba el objeto con polvo de azufre, y se introducía en un horno caliente. Una vez calentado, se daba el pulimento final con una mezcla de vaselina, grasa de ballena, cera y resina de pino.

2 Cheetham 1984, 11.

3 The Catholic Encyclopedia, Volume I. Copyright (C) 1907

by Robert Appleton Company. Online Edition
Los hornos servían también para, si se deseaba, poder teñir el alabastro, cuyo natural poroso le permite absorber cualquier tono de color si se calienta a la temperatura adecuada. El origen del nombre de esta piedra no está del todo claro; quizá deriva de los vasitos griegos de tipo alabastron, que en ocasiones se realizaban en ella. También pudiera haberse dado el proceso contrario, ya que la fama de estos vasos provenía de la creencia según la cual eran capaces de conservar los ungüentos y medicamentos ${ }^{3}$, fama atribuida sin duda a un tipo específico de material, y no a una forma cerámica. Hay que tener en cuenta además la existencia en Egipto de una ciudad del mismo nombre Alabastra, celebrada por sus pequeños recipientes para perfume, así como por las canteras de este material, que tal vez originara las denominaciones tanto de los vasos como del material. Las evidencias arqueológicas más tempranas del trabajo del alabastro vienen precisamente de Egipto ${ }^{4}$, donde los vasos de piedra formaron parte de los ajuares funerarios al menos desde el período Merimde, anterior al Predinástico. Aunque los vasos más antiguos son técnicamente mediocres, los artesanos egipcios pronto alcanzaron un sorprendente nivel en la talla del alabastro, y desde el Dinástico Antiguo, y sobre todo el Imperio Antiguo, las manufacturas se multiplicaron. Egipcios, griegos y romanos lo utilizaron para revestimientos arquitectónico, para fabricación de vasos (en los que se mezclaban diversos aromas, como por ejemplo incienso del este de África, Cedro del Líbano y jengibre de la India) y tallas de estatuas. La arquitectura paleocristiana para la cubrición de ventanas.

En la península itálica, los primeros indicios sobre el trabajo del alabastro se remontan a momentos etruscos. El alabastro volterrano se considera el de mayor calidad del continente europeo; se halla en depósitos formados en el Mioceno, y es compacto y de aspecto a la vez translúcido y aterciopelado. Todavía hoy Volterra es un importante centro de producción alabastrina. Desde el siglo VIII a. C. los etruscos elaboraron urnas funerarias y relieves con este alabastro, que a veces doraban y pintaban. Los primeros objetos que vieron los romanos en este material fueron pequeñas piezas como vasos o pies de sillas o camas. En el año 64 a.C. Lentulo Espinter enseñó a los romanos ánforas realizadas en este material y cinco años más tarde cono-

Copyright (C) 1999 by Kevin Knight. Entrada "Alabastro".

4 Véanse e.g. los trabajos de Aston 1994, Stocks 1986 y 
cemos la existencia de columnas realizadas con esta piedra en el teatro de Cornelio Balbo. Plinio señaló que vió treinta columnas, más altas que las del teatro Balbo, decorando el comedor de Calixto, un liberto de Claudio. Los romanos buscaron siempre el alabastro de color miel y tuvieron por defectuoso aquel que tenía color blanco.

En la península tenemos constancia de la existencia de urnas de alabastro de dimensiones $\mathrm{y}$ formas variadas que fueron depositadas en los enterramientos fenicios documentados en las costas andaluzas, como por ejemplo en la necrópolis Laurita (Granada) donde se han documentado recipientes de manufactura egipcia procedentes de Menfis, centro especializado en la fabricación de recipientes de alabastro.

Esperamos que la incorporación de nuevos datos en el futuro nos permitirá realizar una visión más global que complete este panorama parcial de la ornamentación escultórica de la villa de El Saucedo.

\section{III.- ORGANIZACIÓN PLANIMETRI- CA Y PROGRAMA ORNAMENTAL ${ }^{5}$.}

Centrándonos en la villa bajoimperial de El Saucedo, ésta se corresponde con la segunda fase de ocupación del yacimiento, en uso desde finales del siglo III-finales del siglo IV d. C., hasta finales del siglo V-comienzos de VI d.C. Se trata de una villa aúlica y podríamos denominarla, a tenor de las estructuras puestas al descubierto como una villa monumental simple alrededor de peristilo (Fig. 3.1 y 3.2). Está caracterizada por la multiplicidad de ábsides, por la riqueza monumental, la adopción de un arte oficial y el gusto por las perspectivas interiores.

El área residencial o pars urbana (la única

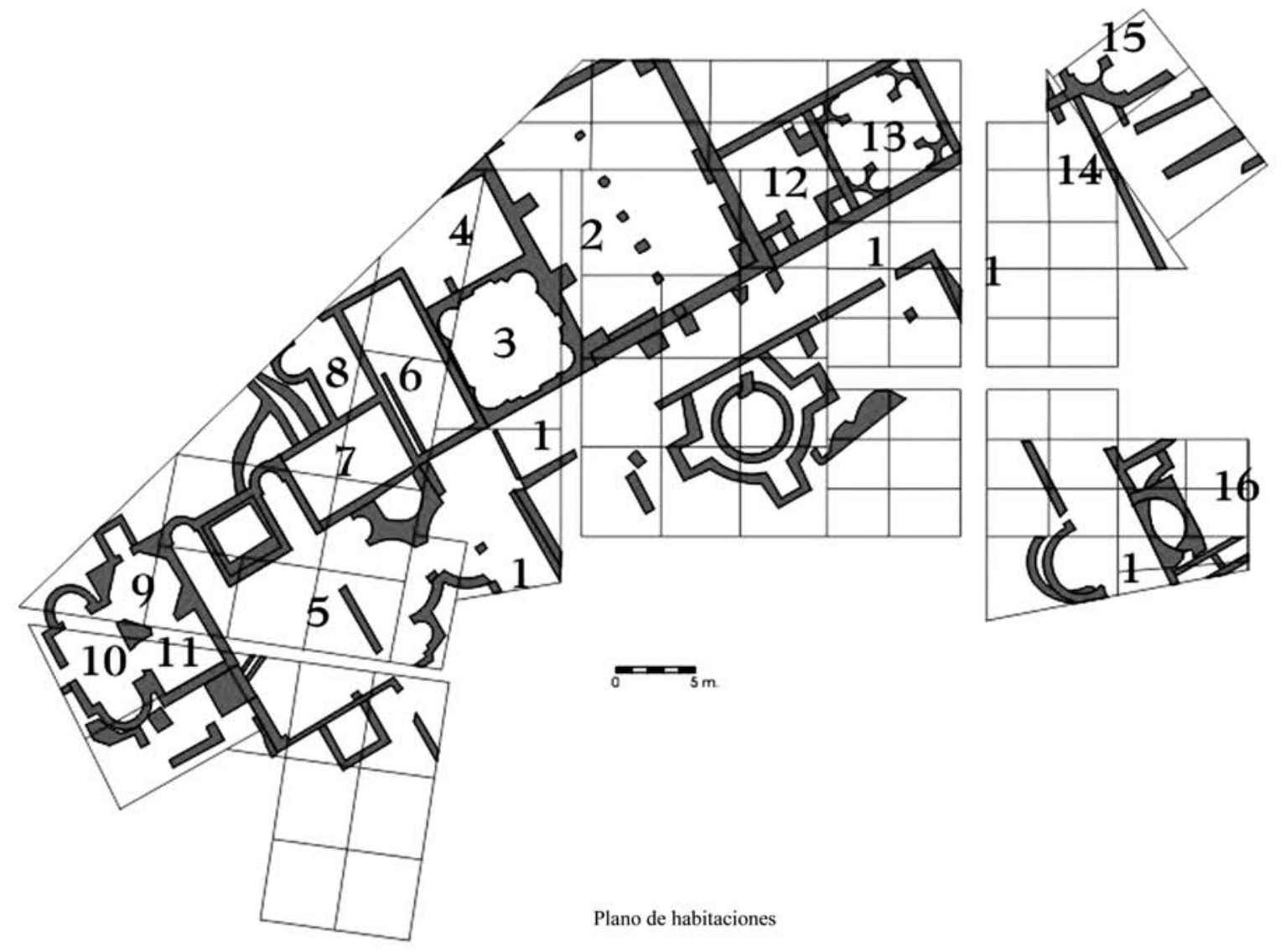

3.1. Plano con proyección de las estructuras arquitectónicas.

5 Para conocer más datos consultar Castelo et alii (2004 a): "Novedades en la interpretación arqueológica de la villa bajoimperial de El Saucedo (Talavera la Nueva, Toledo) y su reconstrucción virtual", Homenaje a Dr. D. Emeterio Cuadrado Diaz, Anales de Prehistoria y Arqueología, 16-17 (2001-2002), 463-476, Murcia. 


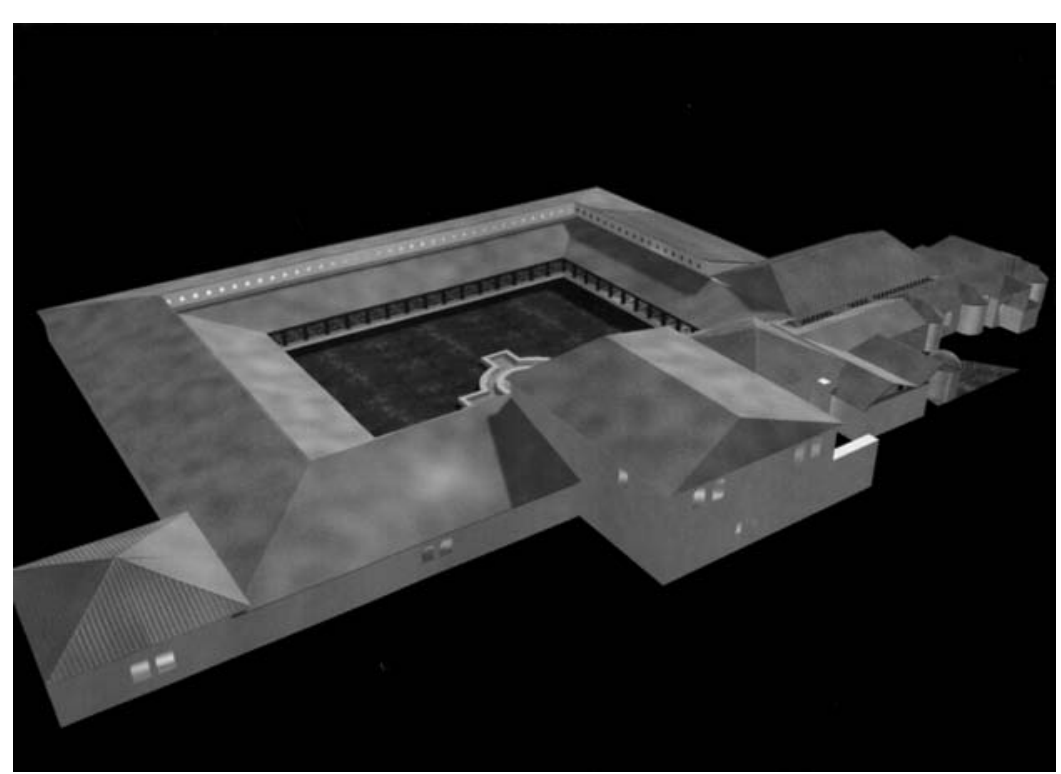

3.2. Reconstrucción de la Villa de El Saucedo.

documentada por el momento), se organiza en torno a un atrio central a cielo abierto $(39 \times 27$ m.) rodeado de una galería porticada. El elemento central del peristilo-jardín lo constituye una fuente ornamental adosada al muro noroeste. Ésta presenta una planta formada por dos círculos concéntricos, el mayor de los cuales se articula en tres brazos cuadrangulares. Un orificio de desagüe abierto en el muro interior comunica ambos canales cuyos suelos son de opus signinum. Peristilos con las dimensiones semejantes al de El Saucedo se encuentran en Santervás (43'50 x 22); Aguilafuente (31'20 x 25); La Malena (25x27); La Olmeda (25); Carranque (35 x 35); Los Casares (43 x 47) (Regueras Grande y del Olmo, 1997,676) o La Torrecilla (Blasco y Lucas, 2000). La fachada principal estaría mirando al sureste, orientación que coincide con las prescripciones dadas por Paladio, escritor del siglo IV d.C. y autor de un tratado de agricultura; con esta orientación se lograba que el edificio estuviera iluminado por el sol durante el invierno y no notar su calor en el verano. El peristilo-jardín fue la fórmula arquitectónica más utilizada como núcleo de distribución de las villas rurales de Hispania. Se trata de la llamada casa mediterránea y aunque está constatada desde época Altoimperial fue un tipo de edificación característica del Bajoimperio (Fernández Castro, 1982,170-171). No obstante no existe un solo módulo, ya que se constatan multitud de variantes locales. Pese a todo, algunos de los paralelos que podríamos citar son las villas de: Liedena (Navarra); La Cocosa (Badajoz) y el Hinojal (Dehesa de las Tiendas, Mérida); Bruñel (Quesada, Jaén); Río Verde (Marbella, Málaga);
La Dehesa de Soria (Cuevas de Soria); Los Villares (Santervás del Burgo, Soria); Quintanares de Río Seco (Soria);La Olmeda (Palencia); Almenara de Adaja (Valladolid); Santa Lucía(Aguilafuente, Segovia) (Fernández Castro, 1982 y García Entero, 2001); La Torecilla (Getafe, Madrid) (Blasco y Lucas, 2000); Los Casares (Armuña, Segovia) y un largo etc. La fuente monumental se caracteriza por presentar una planta centrada con un círculo inscrito en otro concéntrico articulado en tres brazos cuadrangulares, ya que en su cuarto lado se unía al muro perimetral interior del patio. Buena parte de los peristilos romanos contuvieron en su ámbito canales, fuentes de planta semicircular, pozos o estanques que cumplieron una función de carácter ornamental, para aprovechar el efectismo del agua, y a la vez ayudar a mantener el frescor y la humedad necesarios en la conservación de las plantas y árboles del jardín. Ejemplos de esto se han documentado en la villa de Fortunatus (Fraga, Huesca) (Fernández Castro, 1982, 96); en la llamada Casa de Mitra (Cabra, Córdoba) (Fernández Castro, 1982, 112); en la villa de Pujol de Benicató (Nules, Castellón) (Fernández Castro, 1982, 178) y en la villa de El Palmeral (Santa Pola, Alicante) (Sánchez, Blasco y Guardiola, 1986, 39 y 44-45). Fuentes adosadas a los muros perimetrales se documentan en la villa de El Pumar (Jerez de los Caballeros, Badajoz) (Fernández Castro, 1982, 120) y en la llamada villa de Materno (Carranque, Toledo) (Patón Lorca, 2000, 83-91). Otros ejemplos de fuentes con plantas semicirculares adosadas a los muros internos del patio las encontramos en la villa portuguesa de Torres Novas (Villa de Cardilius, Santarem) y en la villa andaluza de Arcos de la Frontera (El Santiscal, Cádiz) (Gorges, 1979, 241470)

El pasillo o corredor sur del peristilo, donde estaría situada la entrada principal, remataría tanto al oeste como al este en ábsides semicirculares. Por el momento solo hemos documentado el ábside SE, pero es lógico pensar que hubiera otro simétrico en el lado SO. Villas de peristilo con uno de los pasillos porticados rematado en uno o dos extremos con ábsides semicirculares se han constatado en la Villa de Memorana (Vega de Ciego, Oviedo); Villa de las Mezquitillas (Cortijo de Fuentidueñas, Écija, Sevilla) y La Sevillana (Badajoz). 
Por lo que respecta a las características constructivas y ornamentales del corredor porticado (1), este presentó, con toda probabilidad, un zócalo compuesto por placas marmóreas de diversa tipología: placas amarillentas de grano fino, compacto y homogéneo con una coloración rojizo-rosada muy intensa; mármol blanco amarillento con una ligera sombra violácea y mármol blanco cándido de grano grueso con cristales visibles.

Desconocemos cómo pudo estar decorado el alzado de los muros de este corredor, pues no se han documentado restos de pinturas murales en el transcurso de la excavación. Sí se han podido recuperar, en cambio, abundantes tejas planas y curvas, éstas últimas decoradas mediante incisiones formando un motivo geométrico a base de cuatro líneas incisas situadas en el centro- con sentido longitudinal- y a ambos lados motivos en segmento de círculo formando una decoración de ochos. Este tipo de ímbrices se han documentado en otros ámbitos de la villa como el oecus; caldarium del complejo termal A; en el posible larario/sudatio; en el caldarium y sudatio del complejo termal B y en la zona de la habitación pavimentada con los mosaicos de los pavos reales.

Tras el análisis del patio porticado, en torno al cual se distribuyen todas las estancias documentadas por el momento, mencionaremos, a continuación, la sala interpretada como oecus y a partir de ella continuaremos nuestro recorrido por las diversas estancias del complejo rural en sentido inverso a las agujas del reloj.

El oecus (2) es una enorme estancia, de unos $183 \mathrm{~m}^{2}$. Presenta una planta rectangular y se encuentra situada, al norte, en el centro del lado mayor del peristilo, encontrándose la fuente monumental justo enfrente de la misma. Su puerta mira al mediodía, siguiendo la ancestral tradición oriental de las salas de aparato y audiencia, rasgo que acentúa el carácter oficial de estas aulas. Salas semejantes a la aquí documentada podemos citar las de Los Casares, La Olmeda, San Martín de Losa (Burgos), La Malena (Zaragoza) y Aguilafuente (Segovia).

Planteamos que esta habitación sea el oecus ya que en este tipo de villas de peristilo predomina la organización polar, con la habitación principal se situada en el eje. Responde a las normas dadas por Vitruvio para estos salones en el capitulo VI "De los salones a la griega", recogido en su obra Los Diez Libros de Arquitectura "sitúese de cara al septentrión y hacia donde se vean vegetales, con sus puertas en medio".

En cuanto al tipo de pavimento que pudiera haber tenido poco podemos decir al respecto, quizá estuvo solado con un suelo de madera o, más probablemente, de opus sectile, ya que no han llegado hasta nosotros restos de pavimento musivario o de baldosas (ya sean cerámicas o de piedra), tan solo un suelo de argamasa. Paladio en su obra recoge como posible pavimentación de estancias señoriales los suelos de maderas nobles confeccionados con encina, roble, haya o fresno.

Conocemos el hallazgo de fragmentos de mármol documentados en el transcurso de las investigaciones realizadas en los años 1982 y 1986, mármoles que pudieron formar parte tanto de un revestimiento parietal como pavimental. Esta sala, en época de funcionamiento de la basílica de culto cristiano, fue muy reformada $y$ transformada en almacén o torcularium, dependiente de la iglesia rural situada en el apodyterium/frigidarium. La cubierta original de esta sala debió hundirse, lo que implicó la construcción de una nueva techumbre, esta vez, de armazón de madera, sustentada por una hilera de columnas de granito de diferentes módulos.

Se han constatado dos columnas de caliza marmórea de diverso módulo en la campaña de excavación de 2003, pero éstas no se encuentran en su posición original. Nada podemos decir del acabado final de las paredes.

La habitación interpretada como larario/apodyterium (3), presenta una peculiar planta. Se encuentra situada al este del tepidarium del Complejo Termal A y tiene una forma cuadrangular con un ábside semicircular en cada esquina $\mathrm{y}$ tres pequeñas exedras cuadrangulares, de unos $25 \mathrm{~cm}$. de profundidad en los muros norte, sur y este. Desconocemos el uso exacto que pudo tener ya que no se halló ningún vestigio arqueológico que pudiera arrojar alguna luz al respecto, si bien estancias de planta y tamaño semejante han sido interpretadas en otros yacimientos como lararios o estancias termales. Así podemos citar las plantas constatadas en los villas de Los Quintanares (Rioseco, Soria, identificado como un larario o santuario familiar); Los Villares de Santervás del Burgo (Soria, Larario); Centcelles (Tarragona) y Villa de La Olmeda (Palencia, frigidarium).

Son pocos los testimonios arqueológicos que nos permiten conocer su acabado final. El zócalo de las paredes, a tenor de los restos conservados in situ, presentaría una pintura de color rojo. A través de un fragmento de argamasa con decoración moldurada, la misma que se ha documentado en la sudatio del complejo termal B, podemos determinar que la zona alta de la pared presentaría una decoración moldurada integrada por un baquetón liso, una franja decorativa a base de rombos, un friso decorado y un baquetón liso. La presencia de ladrillos-dovela nos 

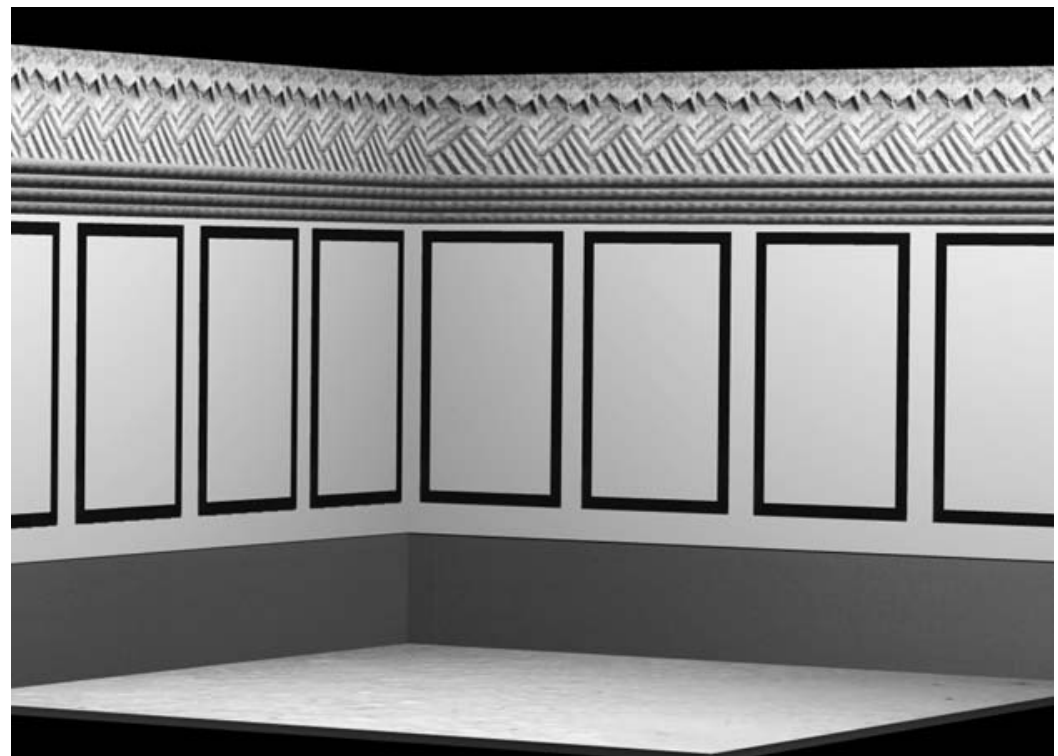

4.1. Reconstrucción del Larario/Apodyterium.

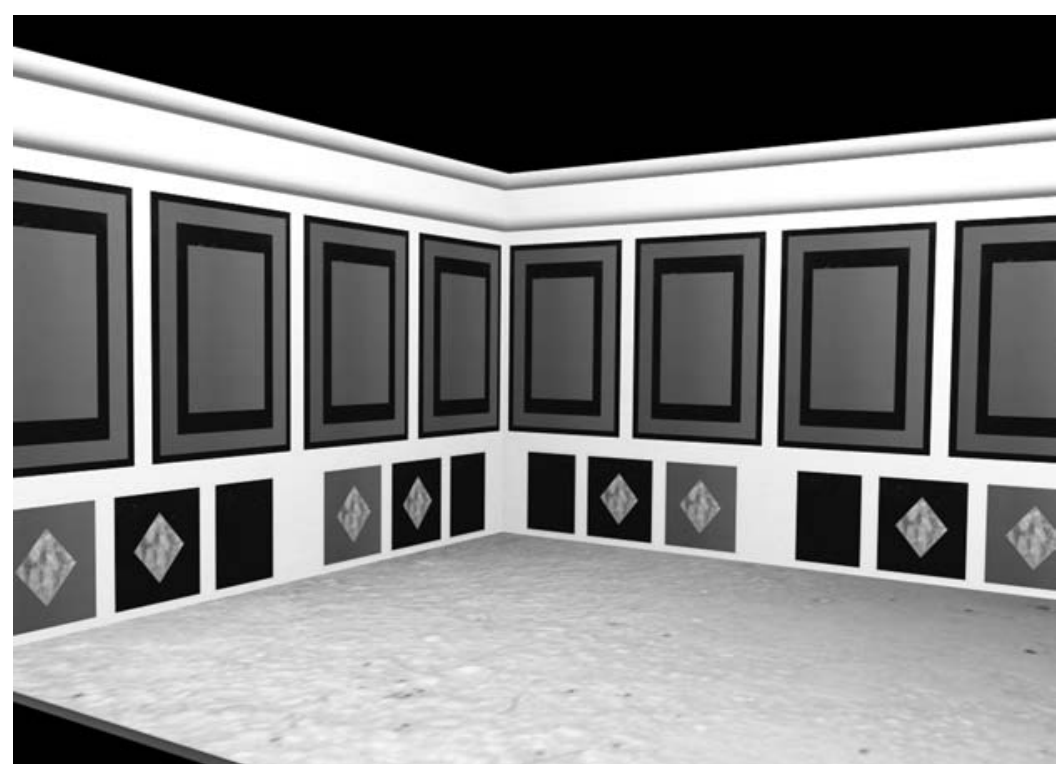

4.2. Reconstrucción del Tepidarium. Complejo Termal A Dibujos realizados por J. Mellado.

indica una cubierta abovedada (Fig. 4.1).

Complejo Termal A. Está compuesto por varias estancias: Tepidarium (6), de planta rectangular, de unos 16 metros cuadrados dividido en dos ambientes. Al conservarse completo el suelo de esta habitación no hemos documentado los ladrillos característicos del sistema de hypocausis, que sin duda debieron tener las mismas características que los constatados en el resto de las habitaciones calefactadas halladas en la villa. Esta estancia presenta dos tipos de pavimentaciones: un suelo de baldosas al norte y un suelo de opus signinum al sur. Durante el proceso de excavación se pudo apreciar que el suelo de bal- dosas podría corresponder a una repavimentación, pues éstas montan sobre el enlucido del muro. A través de una rotura se ha podido conocer las diferentes partes que integran éste: capa de material de derribo formada por fragmentos de ladrillos, piedras etc de $2 \mathrm{~cm}$. de espesor; capa de argamasa del mismo grosor y por último el enlosado. En cuanto a la decoración del alzado de las paredes hemos podido documentar que el zócalo presenta como motivo ornamental pinturas murales de estilo crustae o I Estilo Pompeyano; pinturas que se han conservado- en relativo buen estado- en un tramo del murete de ladrillos - que crea en el lado oeste una cámara de calor. Podemos a través de su análisis reconocer que tipos de mármoles se quisieron representar, quizá los mismos que los empleados en los zócalos de otros ámbitos de la villa. La seriación conservada es como sigue: placa rectangular de mármol negro o gris oscuro; placa de mármol gris; placa de mármol gris con crustae en forma de losange en mármol brocatel; placa rectangular de mármol negro; placa de pórfido rojo con crustae en forma de losange de color brocatel; placa de mármol brocatel (Fig. 4.2). Es posible que este ritmo compositivo se repita a lo largo de todo el zócalo de la habitación. El I Estilo Pompeyano llegó a la península a mediados del siglo II a.C. tal y como queda constatado en los hallazgos documentados en Alcalá de Azaila (Teruel), Contrebia Belaisca (Zaragoza) y Sekaisa (Belmente de Calatayud). En un primer momento este estilo de crustae sirvió para decorar las zonas medias de la pared. Después, en época Bajoimperial, estan presentes en los zócalos, muy posiblemente con el fin de ceder la parte noble de la pared a otras decoraciones (Guiral Pelegrin, 2000, 23). En Mérida, las primeras producciones de este estilo se realizaron en el siglo I d.C. para desaparecer en el siglo II y resurgir en el s. III con mucha fuerza, momento en el que se ponen de moda en occidente, para mantenerse hasta finales del siglo IV (Hernández Ramírez, 2000, 50-51). Responden, en esencia, a una moda seguida de forma general en todo el imperio (Vaquerizo Gil, 
1995, 81-103). Así por ejemplo podemos citar las pinturas documentadas en Barcelona, donde las crustae se alternan con la representación de un jinete, interpretado como el dominus; o las de la Casa Basílica (Mérida), fechadas en época de Teodosio e interpretadas por Mostalac Carrillo, nuevamente, como el dominus junto a su familia. Sagunto (Valencia) y Almedinilla (Córdoba ofrecen así mismo, espléndidos ejemplares de imitaciones de mármoles (Guiral Pelegrin, 2000, 35). En Portugal estos paneles de imitación de mármol se documentan, por ejemplo en Torre de Palma (Nunes Pedroso, 2000, 73-100). En ámbitos termales pinturas del I Estilo Pompeyano se han documentado en la sudatio de la villa del Camino Viejo de las Sepulturas (Albacete); en la sala calefactada de la isla del Moral (Calunga, Asturias) y en la gran sala de La Olmeda (Palencia) (García Entero, 2001, 354).

La zona media debió completarse con pinturas del Segundo Estilo Pompeyano debido a la multitud de fragmentos de estucos documentados. La zona alta remataría con molduras de color amarillo. La estancia tuvo pequeñas ventanas que permitieron gozar del calor y de la luz del sol al atardecer y contemplar el paisaje circundante. Su existencia se intuye por el hallazgo de un fragmento de reja de hierro, de varios fragmentos de vidrio de ventana de diversos colores (verde esmeralda, verde amarillo, azul oscuro, azul celeste, etc.), así como de molduras estucadas en amarillo que conformarían una ventana. En el tepidarium de las termas de San Juan de Maliaño (Camargo, Cantabria) se localizó una o varias ventanas a través de la documentación de vidrios (Muñoz Fernández, 2000). Fue a partir de las últimas décadas del siglo I d.C. cuando comenzó a utilizarse el vidrio en construcción para cierre de oculi y ventanas, utilizándose la técnica de fundido y prensado. Fragmentos de vidrio plano fundido para ventana se hallaron en la ciudad de Caesaraugusta de época de Tiberio y en la ciudad de Celsa de la época de Nerón (González Tascón, 2002, 51). El zócalo exterior de la habitación recibió también decoración pintada, en este caso se imitaron sillares escuadrados; este tipo de pintura se ha documentado en Contrebia Belaisca (Botorrita, Zaragoza), y en el Templo de Azaila (Teruel), con cronología altoimperial (Mostalac Carrillo, A. y Guiral Pelegrin, C. 1998, 323, fig. 1a y 1b). Frigidarium (7). Esta habitación de planta rectangular de 30 metros cuadrados aproximadamente, con un ábside semicircular en su lado este, está pavimentada enteramente con capas de opus signinum, y en su unión con los muros presenta una moldura de cuarto de bocel que recorre todo el perímetro de la estancia. Nada más podemos decir del programa decorativo de esta estancia, ya que estaba completamente arrasada. Caldarium (8). Estancia situada al lado occidental del tepidarium, con una superficie aproximada de 18 metros cuadrados que remata en su flanco noroccidental por una exedra semicircular que debió de cumplir la función de alveus o bañera de agua caliente. El caldarium de El Saucedo no se aparta de las características formales de otras salas de baños calientes, García Entero dice que se trata de "estancias generalmente de planta rectangular o cuadrangular rematadas como señala Vitruvio, en uno o en varios flancos por recintos para la toma de baños calientes (alvei)". La presencia de un solo espacio para la localización del alveus es la situación más común en los balnea domesticos rurales, así por ejemplo, podemos citar los recogidos por García Entero para la provincia de la Tarraconense: Torre de la Cruz (Alicante); Sant Amaç de Viladés (Rajodell, Barcelona), Can Sans (Barcelona); Font del Vilar (Gerona); El Solán (León); Balsapinta (Murcia); Foz de Lumbier (Liédena, Navarra); Soto de Ramalete (Navarra); necrópolis paleocristiana (Tarragona); El Cogoll (Tarragona), Sádaba (Zaragoza), etc (García Entero, 2001, 323).

Los materiales documentados nos han permitido establecer las características constructivas y decorativas de esta sala calefactada: el suelo del área o de la cámara de calor se compuso de un pavimento de guijarros sobre el que se superpuso una fina capa de opus signinum, actualmente desecha en muchas zonas. Hemos podido atestiguar el uso de: ladrillos bessales para la construcción de las pilae y de las arquerías del hypocaustum. Esta función, de los ladrillos bessales, como elementos de las pilae ya fue señalada por Vitruvio, aunque también es posible encontrarlos con otros usos como por ejemplo: formando parte de los muros refractarios de los hipocaustos, como sucede en Gijón (Fernández Ochoa, Zarzalejos y Morillo, 1999, 300), así como para usos secundarios como la formación de arcos y confección de pavimentos, empleándose, en éste último caso como baldosas.

En el caso de los complejos termales de El Saucedo (A y B) y en concreto en las salas calefactadas (caldaria, tepidaria y sudatio) el sistema de hypocausis, tal y como hemos publicado en diversas ocasiones, corresponde al sistema de arcos, sistema que está mayoritariamente presente entre los conjuntos rurales lusitanos, y en cambio fue muy poco utilizado en los edificios balnearios de otras regiones, como la Tarraconense.

Su empleo parece una respuesta a problemas puntuales de carácter funcional aparecidos tras el 
uso de las llamadas pilae clásicas, si bien su utilización no supuso el abandono de este último mecanismo. Según Vitruvio las pilae debían situarse sobre el área del hypocaustum de tal forma que pudieran intercalarse ladrillos de dos pies (García Entero, 2001, 338).

La altura que conservan las pilas de los hypocausta de El Saucedo es de unos $63 \mathrm{~cm}$., para el caldarium del complejo termal A y $78 \mathrm{~cm}$. para el caldarium de ábsides contrapuestos del complejo termal B. Se siguen, por tanto, las recomendaciones de Vitruvio quien indicaba que éstas debían alcanzar los dos pies (59'2 cm.), las de Palladio, quien señala que debían tener dos pies y medio (74 cm.), y las de Faventius quien en el siglo IV d.C. escribió una versión abreviada del Tratado de Arquitectura de Vitruvio (De diversis fabricis architectonicae), donde indicó que la altura alcanzada en los baños privados fuera de dos pies y medio y para termas públicas de tres pies $\left(88^{\prime} 8\right.$ $\mathrm{cm}$.). Por lo general es difícil precisar la altura de las pilae dado el estado de conservación que éstas suelen presentar, no obstante la información disponible permite afirmar que los conjuntos presentaron una gran variedad en lo que respecta a la altura de las cámaras de calor. Los ladrillos bipedales documentados en el caldarium fueron utilizados, en esta ocasión, no solo para la confección del pavimento situado sobre las arquerías sino también para la realización de los basamentos de las pilae. Este tipo de later, usado en los complejos termales, apoyados sobre las pilae formaban una superficie continua, en palabras de Vitruvio: se levantarán unos pequeños pilares de ladrillo de ocho pulgadas tan distantes entre sí que sobre ellos puedan colocarse ladrillos de dos pies; su altura será también de dos pies: constrúyanse con arcilla amasada con pelo, y encima se sentarán dichos ladrillos de dos pies, que sustentarán el pavimento" (Vitruvio, $\mathrm{X}, 45-4,5)$. Sobre ella se podía verter una gruesa capa de opus signinum, sobre la que se colocaba el pavimento visto que podría incluir materiales lujosos tales como el mármol o el mosaico (Fernández Ochoa, Zarzalejos y Morillo 1999, 296-298). El opus signinum de nuestro caldarium presenta un gran espesor y tiene motivos decorativos pintados en colores negro y rojo. Éstos podrían corresponder al dibujo previo realizado por el maestro encargado de confeccionar el pavimento musivario, hoy perdido en su totalidad, pero del que se conservan algunas teselas sueltas. Esta pavimentación (signi- num y mosaico) debía de construirse de tal forma que protegiera el interior de la habitación termal de los gases y humos procedentes de la cámara de calor, al mismo tiempo que se evitaban temperaturas excesivamente elevadas. En cuanto a los paramentos de la sala caliente conocemos el empleo de tubos espaciadores, clavos de hierro y ladrillos con escotaduras, elementos- todos ellosque formaron parte del sistema de tubulatura o doble pared para la circulación del aire caliente. Esta forma de construir la doble pared se caracteriza por el empleo de ladrillos bipedales, con escotaduras en las esquinas, en forma de ángulo o de cuarto de círculo que forman un espacio por el que se insertaban los tubos espaciadores o clavi coctili; cada ladrillo se apoyaba, por tanto, en cuatro clavi coctili que eran sujetados al muro maestro por largos clavos de hierro con cabeza aplanada, en forma de $\mathrm{X}$ y pasador móvil que permitía ceñir cuatro ladrillos a la vez. El alzado de los muros de la estancia estuvo terminado y embellecido por un zócalo de mármol integrado por piezas correspondientes a un mármol blanco traslúcido muy visible y venaturas irregulares de color gris azulado. El hallazgo de una pieza de mármol blanco de grano fino hemiesférica por uno de sus lados y plana por otro, en el que presenta una protuberancia descentrada en forma de pirámide truncada, dando el aspecto de una especie de clavo pétreo, nos ha permitido sugerir que este y otros ejemplos- no documentadospudieron formar parte de la decoración del zócalo colocados en el centro de las composiciones geométricas formadas por placas de mármol. La zona media estuvo decorada con pinturas murales del Segundo Estilo Pompeyano- a tenor de los abundantes fragmentos de pintura mural docu-

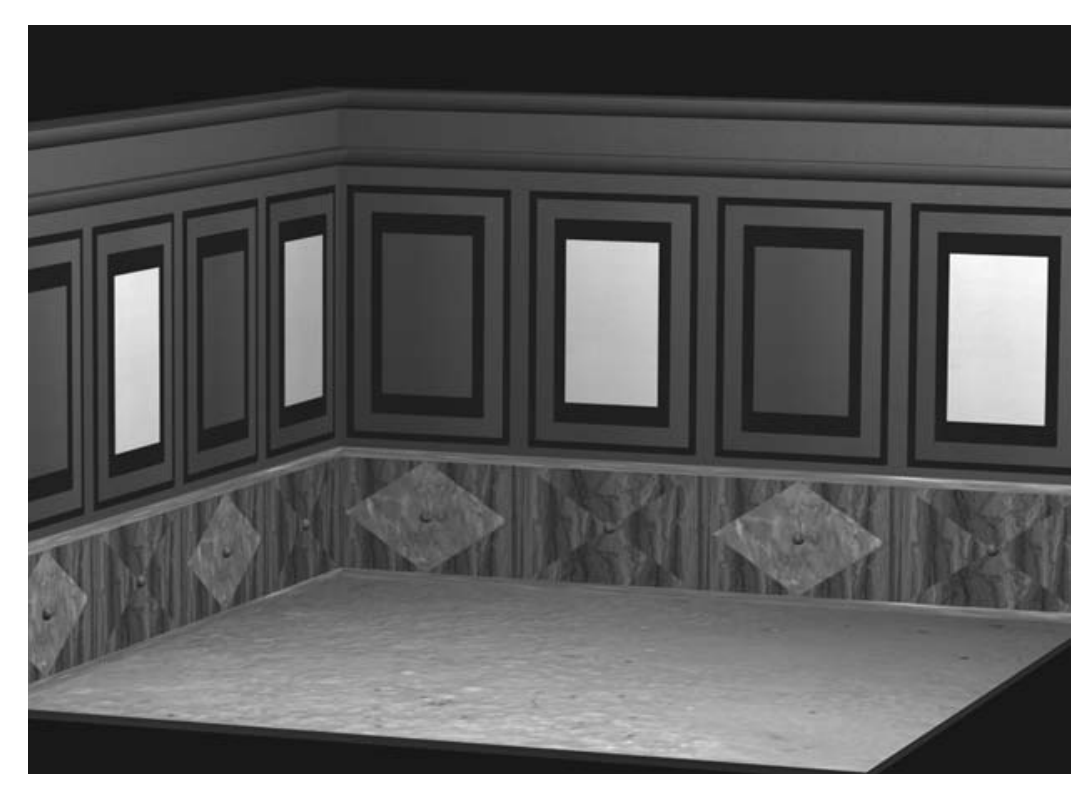

5.1. Reconstrucción del Caldarium. Complejo Termal A 
mentados en el transcurso de las excavaciones. Los paneles estuvieron realizados, al menos, con dos colores- rojo y amarillo- y los interpaneles, pintados en blanco presentarían motivos decorativos geométricos (líneas semicirculares concéntricas en diversos colores, predominando el rojo y líneas serpenteante en azul), vegetales y figurados, de los que hay testimonios en otras estancias de la villa. La zona alta estuvo rematada por molduras pintadas en color rojo (Fig. 5.1). La cubierta, a través de la presencia de ladrillos dovela Tipo 4 a de Sanz Gamo, fue abovedada. Los ladrillos-dovela o briques claveaux fueron empleados para la construcción de las bóvedas que solían cubrir las habitaciones calefactadas, con el fin, de aislar el entramado de madera de la humedad. El calentamiento de las bóvedas evitaba la condensación del agua y molestas gotas frías a los bañistas (Sillièrres et alii, 2000, 196). Este sistema en combinación con las concamerationes conseguía un mejor aprovechamiento del calor, ya que el aire caliente que ascendía por el interior de las paredes podía, así circular, también por las bóvedas (Torrecilla Aznar, 1998, 421) “...Éstas bóvedas en estancias de baños cálidos conviene que sean dos, para que el vapor de agua que el fuego eleva no penetre a la madera de la contignación, sino que se disipe en medio de ellas" (Vitruvio, $X$, 47.9). Vitruvio aconseja, además, construir una abertura circular en la bóveda a fin de iluminar la estancia. No todas las termas se construyeron con este ventajoso sistema de circulación de aire caliente, aprovechando su tendencia natural ascendente y permitiendo, a su vez, su evacuación por el punto más alto de la cubierta (Torrecilla Aznar, 1999, 407).

Apodyterium/frigidarium (5). El acceso a esta sala se realizó desde el peristilo a través de unas fauces en forma de dos exedras semicirculares contrapuestas, similares a los que se observan en la villa Las Mezquitillas (Cortijo de Fuentidueñas, Écija, Sevilla). Estas se encuentran flanqueadas interiormente por dos pequeños ábsides con columnas en sus extremos (se conservan tres de las cuatro basas). Esta habitación se configura como el centro de todo el conjunto termal (A y B), sirviendo como zona de paso hacia el resto de las estancias. Por su lado noroeste se accede a una piscina de agua fría (3' $5 \mathrm{x}$ 2'5 m.), a través de unas escaleras realizadas en ladrillo recubierto por una capa de opus signinum, material que además recubre toda la piscina. García Entero recoge en su trabajo sobre las termas rurales de la Tarraconense numerosos ejemplos con características muy similares: Camino Viejo de las Sepulturas (Albacete); Illeta dels Banyets (Alicante); Can Tarrés (Barcelona); La Mesquita (Barcelona); Can Sans (Barcelona);
Empalme de Caravaca (Murcia); Dueñas (Palencia); Almenara de Adaja (Valladolid); Sadaba (Zaragoza); Mas d'Gras (Tarragona) (García Entero, 2001, 320). Esta se encuentra flanqueada por dos pasillos que rematan en ábside. Toda la estancia presentaba una rica decoración. Por un lado sobresale el pavimento musivario de vistoso colorido, con representaciones geométricas y figuradas de gran belleza. El tapiz central está integrado por una composición ortogonal de octógonos irregulares y cruces latinas adyacentes que forman hexágonos oblongos. Está enmarcada por dos bandas monocromas en negro que enmarcan, a su vez, una línea quebrada de paralelogramos bícromos en rojo y negro, creándose un efecto de relieve. En el centro del tapiz una de las cruces presenta una variante. Está confeccionada con teselas de menor tamaño que las empleadas en el resto del pavimento musivario. Este esquema compositivo lo encontramos de forma generalizada prácticamente e todo el imperio. En los ábsides pequeños de la pared nordeste, la decoración consiste en cráteras de las que emergen follajes con volutas y frutas. Los dos pasillos absidados de la pared noroeste presentaban pavimentos musivarios distintos. Uno de ellos tiene una composición ortogonal de círculos secantes que dejan entrever cuadripétalas y en la zona absidada, dos delfines con las colas enlazadas y enroscadas a un tridente, y el otro se caracteriza por tener una composición ortogonal de octógonos y cuadrados y en el ábside una copa de la que emergen roleos. La composición ortogonal de círculos secantes que dejan entreveer cuadripétalos es un tema tan antiguo como el mundo romano, tuvo un origen helenístico y figura entre las representaciones más frecuentes de la musivaria romana. Los círculos secantes se figuraron en la decoración de los techos. Con respecto al tema de los delfines, aunque no hemos encontrado ningún paralelo exacto estuvo muy extendida en la musivaria. La composición de octógonos combinados con cuadrados es un tema muy adecuado para pavimentos de corredor, en cuanto que es susceptible de una fácil reducción a un módulo que permite su extensión indefinida en longitud y anchura. El esquema es apropiado también para composiciones figuradas, convirtiéndose los octógonos y los cuadrados en simples marcos. Se ha planteado la posibilidad de que este motivo se inspirara en las decoraciones de techos y paredes conservados de diversas maneras. Balil cree que podría postularse un origen inverso ya que, según este investigador, no existen elementos sólidos desde el punto de vista cronológico para establecer la prioridad de una modalidad con respecto a la otra. El tema fue bien conocido en la musivaria 
romana a lo largo de varias épocas; podría, incluso, responder a una creación original de los mosaistas romanos. En Hispania, será en el siglo IV, con el florecimiento que experimenta la musivaria hispánica en los establecimientos rurales, cuando este esquema parece generalizarse ofreciendo abundantes ejemplos. En el centro de la sala destaca la plaqueta sumidero de mármol blanco, anteriormente mencionada, que se comunica con un canal de desagüe. Para Mostalac Carrillo esta pieza podría corresponder a época Teodosiana (Mostalac, 1997, 599). En cuanto al alzado de los muros, nos encontramos con un zócalo formado con placas de mármol blanco amarillento de grano fino con cristales blancos traslúcidos visibles y venaturas irregulares de color gris azulado y placas de mármol blanco ligeramente amarillento de grano fino, compacto y homogéneo. La zona media de la pared y a tenor de los fragmentos de pintura mural documentados (rojos, azules, ocres y verdes) debió presentar- como el resto de las estancias de El Saucedo, un Segundo Estilo Pompeyano. Los paramentos exteriores de esta habitación también presentaron pinturas murales, constatadas en el zócalo. Sobre las juntas de argamasa se aplicó una línea pintada en color negro, línea que circunda las piedras y siguen su forma poco regularizada, diseño que se completa con trazos cortos y radiales del mismo grosor y color. Según los vanos atestiguados y la disposición de las estancias V. García Entero nos ha sugerido que el recorrido sería el habitual, dado que desde el apodyterium/frigidarium se pasaría al frigidarium y desde éste al tepidarium para realizar, a continuación un recorrido retrogado para finalizar el circulo.

Complejo termal B. Está compuesto por tres salas calefactadas.

Sudatio (9). Se trata de una habitación de planta octogonal con una superficie aproximada de 16 metros cuadrados. Este tipo de planta fue muy utilizada durante el Bajo Imperio en aulas señoriales y habitaciones termales, así como en la arquitectura cristiana (martiria y baptisterios). En su muro noroeste comunica, por un estrecho vano, con una pequeña estancia de planta rectangular, cuya funcionalidad desconocemos. En anteriores ocasiones habíamos apuntado la posibilidad de que se tratara de un alveus o bañera de agua caliente, pero por sus características actualmente planteamos que podía tratarse de un registro de limpieza; dadas las dimensiones de este complejo termal quizás no fuera suficiente el acceso al hypocaustum a través del praefurnium. La disposición de su planta y sus características constructivas nos remiten a paralelos cercanos documentados en el conventus emeritensis, así como fuera del ámbito peninsular. Hemos podido determinar que el suelo del área o cámara de calor estuvo formada por una capa arcillosas muy compacta con guijarros de pequeño tamaño y fragmentos de ladrillos. Según Vitruvio, las áreas de los hypocausta debían pavimentarse con ladrillos sesquipedales, aunque Palladio recomienda la colocación de ladrillos bipedales (59'2 cm.) "El piso de estas estancias de baño cálido se hará así; se pavimentará con ladrillos anchos de pie y medio en quadro, dándole tanto declivo hacia la boca del hornillo que arrojando una bola no pueda parar en él, y se venga a la boca del horno, de este modo la llama se extenderá naturalmente por debajo con más facilidad" (Vitruvio, X, 45, 3-4). Esta característica constructiva no es necesaria para el buen funcionamiento del sistema de hypocaustum y dado el escaso número de balnea en los que está presente, la no adopción de esta norma vitruviana, pudo responder a motivos de carácter económico. Los ladrillos bessales que se han recogido fueron empleados para la construcción de las pilae y arquerías que formaron parte de la suspensurae, algunas de ellas conservadas in situ; los ladrillos bipedales documentados formaron parte del suelo de esta habitación integrado también por una capa de opus signinum y pavimento musivario, éste último completamente destruido y hundido como consecuencia del desplome de la cubierta. A través del hallazgo de clavi coctili o tubos espaciadores tipo 4 a de Sanz Gamo conocemos la existencia de doble pared para la circulación del aire caliente.

Son relativamente escasos los ejemplos en los que se puede especificar el mecanismo utilizado en el sistema de tubulatura de los edificios balnearios, debido al estado de ruina o a las propias circunstancias del hallazgo. Se conocen, pues, escasos restos de concamerationes conservadas insitu; así podemos mencionar los ejemplos citados por Fernández Ochoa de la sudatio de las Termas del Padre Blanco (Astorga, León); las sudationes de Gijón; los baños privados del Barrio de la Morería de Mérida; termas del oeste de Mirobriga; en Baelo; en Arcobriga, Bañales y León (Fernández Ochoa, Zarzalejos y Morillo, 1999, 299).

Los clavi coctili son un material que normalmente no es asociado al sistema de calefacción parietal y que es obviado de forma generalizada por los investigadores o interpretado de forma equivocada. Las piezas de cronología más antigua corresponden a época augustea y su uso se generalizó a partir de la segunda y tercera centurias, siglos a los que pertenecen numerosas piezas, documentándose también en conjuntos 
bajoimperiales. Atendiendo a cuestiones de distribución geográfica parece que nos encontramos ante unas piezas muy generalizadas, a partir del siglo I d.C. en la costa este de la península, fundamentalmente en Cataluña donde es evidente cierta concentración, levante y penetraciones hacia el interior en el valle del Ebro y área de Albacete (García Entero, 2001, 344).

Sanz Gamo distingue, para la península ibérica, cinco subgrupos, siendo el tipo 4 el más abundante en la península, ya que su hallazgo constituye dos tercios del total de los clavi coctili, por ella estudiados.

La abundancia de variantes aboga por la idea de producciones locales, en talleres especializados probablemente en materiales constructivos y anfóricos. Estos talleres recibían encargos puntuales de materiales para concamerationes destinados a algún conjunto termal o villa en construcción. La falta de elaboración seriada y continúa de estas piezas produjo diferencias morfológicas entre las piezas de un mismo lote.

Conocemos que los clavi coctili se situaban a distancias regulares, de modo que sus improntas quedan, algunas veces, en forma de oquedades en el muro maestro (Camino Viejo de las Sepulturas, Balazote, Albacete). En Baelo Claudia (Tarifa, Cádiz) se han documentado estas piezas in-situ (Torrecilla Aznar, 1999, 399).

La presencia de adobes - algunos de grandes dimensiones- nos indicaría que una parte del alzado de los muros estaría realizada con este material constructivo, sistema empleado en otras

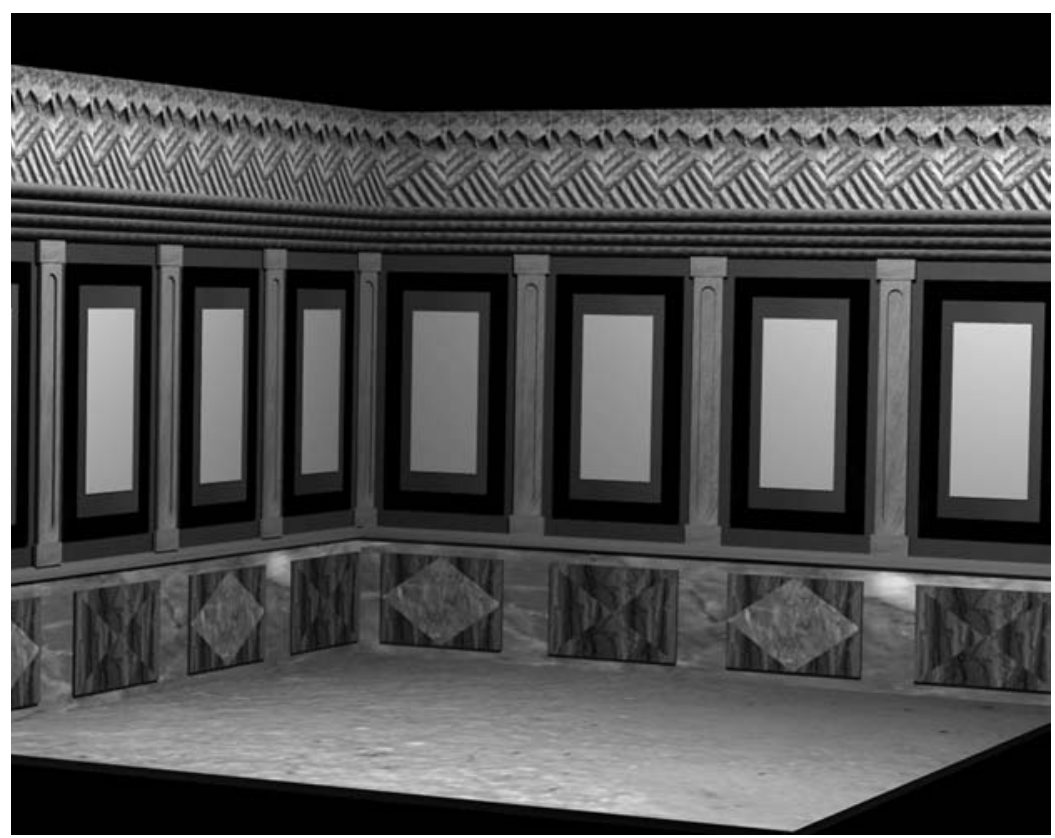

5.2. Reconstrucción del Sudatio. Complejo Termal B. Dibujos realizados por J. Mellado. habitaciones de la villa. En cuanto al embellecimiento de las paredes hemos podido constatar la presencia de un zócalo de mármol, se trata como en los casos anteriores de mármol blanco amarillento crema de grano fino. La zona media del paramento la hemos restituido hipotéticamente de la siguiente manera: se combinaron pinturas murales del Segundo Estilo Pompeyano con pilastras de argamasa con acanaladura central. La zona alta se decoró a base de molduras de argamasa con diversos motivos decorativos geométricos: baquetón liso; franja decorativa formada por rombos, un friso decorado y por último, un baquetón liso, se trata de la misma moldura que la documentada en la habitación denominada como larario/apodyterium (Fig. 5.2).

Caldarium (10). Presenta una planta rectangular de aproximadamente de diecinueve metros cuadrados con dos ábsides semicirculares contrapuestos que albergan sendos alvei a los que se accedería a través de escaleras. Caldaria de esta tipología se han localizado en Can Tarres (Barcelona); La Mesquita (Sant Boi de Llobregat, Barcelona), donde la planta del caldarium con doble cabecera absidada es similar a la documentada en El Saucedo (García Entero, 2001, 324). El suelo del área estuvo integrada por una capa de tierra arcillosa, muy compacta con guijarros de pequeño tamaño y fragmentos de ladrillos, tipo de pavimentación muy frecuente en las área de los hypocausta peninsulares. Como en los casos anteriores hemos recogido ladrillos bessales para la realización de las pilae y arquerías, conservadas-algunas de ellas in situ y para la construcción de unos muretes que apoyan en el muro semicircular de mampostería y sobre los que se asentó el opus signinum que pavimentó la la bañera del ábside norte, a la que se accedía por medio de unas escaleras conservadas in situ. Constatamos el empleo de los ladrillos bipedales que formaron parte de la suspensura y de los arcos que ponían en comunicación el caldarium con el tepidarium y el tepidarium con la sudatio, al nivel del hypocaustum. Este tipo de ladrillo también se documentó en la construcción del muro de cerramiento de la piscina situada en el ábside sur, en concreto para regularizar el paramento formado por mampuestos de granito en el exterior e interior, relleno de argamasa, cal y arena con ripios de granito, tejas y ladrillos fragmentados. Los ladrillos sesquipedales se 
emplearon en la construcción del murete de ladrillos que se documentó bajo la bañera sur. El pavimento del caldarium, además del empleo de ladrillos bipedales estuvo integrado por una gruesa capa de opus signinum sobre la que se asentó el pavimento musivario, completamente destrozado. A través de algunos fragmentos de cierto tamaño hemos podido distinguir que la alfombra tuvo un motivo geométrico a base de escamas o imbricaciones, composición antigua que se repite a lo largo de toda la geografía musivaria romana pero que gozó de gran predilección en época bajoimperial, donde encontramos un gran número de ejemplares fechados entre los ss. IV$\mathrm{V}$ d.C. No es frecuente que los pavimentos musivarios se apoyaran sobre una gruesa capa de signinum, generalmente se colocaban directamente, con su cama de preparación sobre los ladrillos bipedales. Los clavi coctili- documentados en gran número- nos advierten de la existencia de una doble pared para la circulación vertical del aire caliente. Se ha podido determinar la existencia de chimeneas (impressi patietibus tubi y según Séneca cuniculi o tubuli) empleadas para el perfecto funcionamiento del sistema de hypocausis en las cámaras de calor. Éstas eran adosadas, encastradas o enmuradas en los paramentos y conducían el humo y los gases producidos por la combustión hacia el exterior del edificio. Fueron esenciales para garantizar la circulación del aire caliente por todos los rincones de las estancias calefactadas. Los paramentos se embellecieron con un zócalo revestido con placas de mármol blanco y amarillento de grano fino con cristales traslúcidos muy visibles y venaturas irregulares de color gris azulado. Este tipo de revestimientos de lajas de mármol formando parte de los zócalos de las salas o de la totalidad de los lienzos, se ha documentado en algunos conjuntos termales como por ejemplo en el Camino Viejo de las Sepulturas (Albacete); en Baños de la Reina (Calpe, Alicante) o en la Torre de la Cruz (Alicante) (García Entero, 2001, 353). El uso del mármol, tal y como expresa vaquerizo Gil "dibuja ambientes de lujo en los que el mármol representa un elemento cotizado, de aparato y al que no se tiene acceso de forma abierta, muy posiblemente por limitación económica, de oferta o simplemente de distribución" (Vaquerizo Gil, 1995, 81-103). La zona media debió presentar una decoración pintada del Segundo Estilo Pompeyano. No hemos documentado ningún elemento que nos permita conocer como se decoró la parte alta del paramento. A través del hallazgo de un fragmento de reja de ventana y algunos vidrios de ventana de diversos colores podemos determinar la existencia de estas, que estarían ubicadas en los ábsides norte y sur. La presencia de ladrillos dovela nos habla de una cubierta abovedada.

Tepidarium (11). Sala de planta rectangular de unos 16 metros cuadrados. Presentaba el suelo del área igual que el resto de las habitaciones calefactadas de este complejo termal. Los ladrillos bessales, los fragmentos de opus signinum y la abundancia de teselas nos indican que las características de la suspensura no varió con respecto al resto de estancias. La documentación de adobes, nos indica que fueron empleados para completar el alzado de los muros. No conocemos el desarrollo de la decoración a excepción que la parte superior de la pared y en su unión con el techo presentó molduras estucadas en color rojo.

En este complejo termal B, el itinerario sugerido por García Entero podría ser: gran apodyterium, tepidarium y desde aquí acceder bien a la sudatio octogonal, bien al caldarium biabsidado, siendo el plan de uso lineal simple de recorrido retrógado, aunque en las estancias calientes el circuito puede ser circular. Ambos complejos termales corresponden a una misma fase constructiva, por lo que podríamos estar ante unas termas dobles, características de las grandes villae bajoimperiales, tal y como nos ha sugerido $\mathrm{V}$. García Entero. Así el complejo termal A, mucho más sencillo, estaría destinado a uso cotidiano, por parte del dominus y su familia, mientras que el complejo termal B, más monumental, sería utilizado tan solo en grandes ocasiones.

Continuando el sentido contrario a las agujas del reloj debemos destacar la existencia de un Pasillo en el ala este. En este caso desconocemos el tipo de pavimentación que hubo aunque conocemos cómo podría ser el desarrollo de la decoración en la zona media y alta de la pared. La zona media estuvo decorada por pinturas del Segundo Estilo Pompeyano integradas por marco negro relleno de color rojo y zona alta pintada en tono granate.

Detrás de este pasillo se encuentra la habitación pavimentada con opus tesellatum de motivos geométricos y pavos reales con las colas explayadas, entre otros motivos. Apenas tenemos detalles constructivos de esta estancia pues fue excavada por miembros del Museo de Santa Cruz (Toledo), antes de nuestras intervenciones arqueológicas, sin embargo conocemos bien el tipo de alfombra musivaria, a través de un dibujo y de los fragmentos conservados en el Museo de Santa Cruz. La planta central cuadrangular de esta sala se decora con un mosaico compuesto por una estrella de ocho puntas obtenida a través de la unión de dos cuadrados en lacería de trenzas acantonada con rombos. Comenzando por el exterior se observan un par de cintas onduladas 
en trenza formando un círculo; el espacio que queda en el centro se rellena con hojas de hiedra o hederae. Para Fernández Galiano, las hojas de hiedra tuvieron un carácter simbólico, profiláctico y benéfico. No obstante, es difícil saber hasta que punto este motivo conservó su valor simbólico tras una larga serie de repeticiones. Las cintas onduladas en trenza encierran un octógono que a su inscribe una estrella de ocho puntas obtenido a través de la unión de dos cuadrados en lacería de trenzas acantonada con rombos. En el interior de la estrella se cobija un octógono decorado con guirnalda vegetal. Este motivo corresponde, en líneas generales, a motivos y esquemas que, si bien tienen todos una tradición que arranca en ocasiones en pavimentos del siglo I d.C., se generalizan, sobre todo, en época bajoimperial. El tema también lo encontramos representado en la pintura mural. En la península ibérica el motivo fue frecuente entre la mitad del siglo II y el siglo IV, aunque su uso será más abundante en época bajoimperial. Según Blázquez, este motivo de estrella de ocho puntas obtenida por la intersección de dos cuadrados surgió por primera vez en mosaicos de la costa levantina y en concreto en la ciudad comercial y minera de Cartagena. Para Reguera Grande el esquema de los dos cuadrados rotativos inscritos en un círculo fueron en época clásica un elemento constante por el gran valor simbólico otorgado a esas dos figuras geométricas. Una de las estancias de planta rectangular cerrada con ábsides que flanquean el ámbito cuadrangular antes mencionado, presenta los siguientes motivos decorativos: trenza de dos cabos que rodea toda la composición geométrica, realizada a base de círculos, cuadrados y rectángulos rectilíneos o carretes. Esta composición tuvo su máximo apogeo en los ss. I y II. Según Mondelo Pardo las composiciones de círculos y cuadrados son poco frecuentes en la península ibérica, donde se manifiesta en los ss. III y IV d.C. Parece que Mérida presenta el prototipo de este tipo decorativo y su ejecución sirvió de acicate para que fuera realizado por otros talleres. Los ábsides contrapuestos presenta un enmarque de trenza de dos cabos y pavos reales de frente con las colas explayadas. La figura de los pavos no es extraña a los pavimentos musivarios, ni tampoco a la pintura mural. Debido a su natural belleza y a su vistosidad tuvo una gran aceptación en numerosas facetas del arte romano. Fue representado frecuentemente en mosaicos africanos, en cambio en la península encontramos pocas representaciones. La otra habitación absidada se pavimentó con un tapiz integrado por hexágonos escutiformes cruzados dejando entrever octógonos, cuadrados y rombos. Presentan como moti- vos decorativos de enmarque meandros en L, cuadrados y trenza de dos cabos contorneada. Los ábsides contrapuestos presentan una composición ortogonal de peltas. Se puede afirmar que la pelta es uno de los elementos más antiguos del repertorio temático de los mosaicos ornamentales romanos. Su notable simplicidad permitió que fuera utilizada como elemento decorativo aislado o formando composiciones. Su utilización fue masiva en Italia desde el siglo II d.C., perdurando hasta el final de la baja romanidad.

Finalmente llegamos a la última estancia constatada por el momento. Se trata de una habitación de planta rectangular que en una segunda fase constructiva del periodo bajoimperial, fue remodelada, levantándose un muro de escasa calidad que la dividió en dos, como resultado quedaron una habitación de planta rectangular y otra en la que se realizaron, en cada una de las esquinas la construcción de dos ábsides contrapuestos, también de muy mala factura. De esta forma, la planta de la habitación presenta un espacio cuadrangular central flanqueado en sus cuatro lados por ámbitos rectangulares rematados en ábsides. Ignoramos el tipo de pavimentación que tenía, tan solo quedaban restos de una capa de argamasa muy descompuesta en algunas zonas, pero sabemos que los muros estaban decorados con pinturas.

Con este trabajo hemos pretendido obtener una visión general sobre las piezas que formaron el conjunto ornamental de la villa de El Saucedo.

Para finalizar, hemos de reconocer que este estudio deja hipótesis y aspectos en los que aún hay que profundizar y que tendrán sus respuestas en nuevos trabajos y los hallazgos arqueológicos que nos ayudarán a concretar los aspectos planteados y poder avanzar en esta línea de investigación.

\section{BibLIOGRAFÍA}

ASTON, B.G. (1994): Ancient Egyptian stone vessels: materials and forms, Heidelberger Orientverlag, Heidelberg.

BLASCO, M ${ }^{\text {a }}$ C. Y LUCAS PELLICER, (Ed.) (2000); "El yacimiento romano de La Torrecilla: de villa a tugurium", Patrimonio Arqueológico del Bajo Manzanares, 4, Madrid.

BORGHINI, G. (ed.) (1998): Marmo Antichi, Roma.

CANTO, A. M ${ }^{\mathrm{a}}$., (1999): El paisaje del teónimo: Iscallis talabrigensis y la aspirina, Religión, Lengua y Cultura prerromanas en Hispania 107-134. Salamanca.

CASTELO, R. et alii., (2004 a): "Novedades en la interpretación arqueológica de la villa bajoimperial de El Saucedo (Talavera la Nueva, Toledo) y su 
reconstrucción virtual", Homenaje al Dr. D. Emeterio Cuadrado Diaz, Anales de Prehistoria y Arqueología, 1617 (2001-2002), 463-476, Murcia

CASTELO et alii $(2004$ b) "Materiales constructivos procedentes del yacimiento romano de El Saucedo (Talavera la Nueva, Toledo" Homenaje a D. Gonzalo Muñoz Carballo, Boletín de la Asociación Española de Amigos de la Arqueología 43.

CASTELO et alii (e.p.) "El Saucedo (Talavera la Nueva, Toledo). Un ejemplo de villa Bajoimperial en la provincia de la Lusitania”, Archivo Español de Arqueología, Madrid.

CHEETHAM, F. (1984): English Medieval Alabasters, Oxford.

CISNEROS, M.,(1988): Mármoles hispanos: su empleo en la España romana, Zaragoza.

FERNÁNDEZ CASTRO, Mª C. (1982): Villas romanas en España, Madrid.

FERNÁNDEZ OCHOA, C.; MORILLO CERDÁN, A. Y ZARZALEJOS PRIETO, M., (1999): Material latericio en las termas romanas de Hispania, El Ladrillo y sus derivados en la época romana, Monografías de Arquitectura Romana, 4, 291- 305, Madrid.

GARCÍA ENTERO, V., (2001): Los balnea de las villae hispanorromanas. Provincia Tarraconense, Monografías de arquitectura romana, 5. serie termas 1, Madrid.

GNOLI, R., (1988): Marmora Romana, Roma.

GORGES, J.G. (1979): Les villes hispano-romaines. Inventaire et Problématique archeólogiques, Paris.

GONZÁLEZ TASCÓN, I., (2002): La ingeniería civil romana, Artifex. Ingerieria romana en España, 33-76.

GUIRAL PELEGRIN, C. (2000): "La pintura romana en España. Aportaciones recientes", La pintura romana antigua. Actas del Coloquio Internacional,21-35, Mérida (Mérida, 1996).

KOPPEL, E.M. (1993): "La escultura del entorno de Tarraco: las villae", Actas de la I Reunión sobre Escultura romana en Hispania, Mérida.

LÓPEZ LÓPEZ, I. M. (1998): Estatuas masculinas togadas y estatuas femeninas vestidas de colecciones cordobesas, Córdoba.

MARTÍN AGUADO, M., (1965): Para la historia de Talavera, Provincia, s.p., Toledo.

MAYER OLIVÉ, M. (2001): "Epigrafía de Carranque", Carranque. Centro de Hispania romana ,119-135, Alcalá de Henares.

MOSTALAC CARRILLO, A., (1997): "El programa pictórico de la estancia absidada $\mathrm{F}$ de la Casa Basílica de Mérida", Congreso Internacional La Hispania de Teodosio, vol. 2, 581-603.
MOSTALAC CARRILLO, A. y GUIRAL PELEGRÍN, C. (1998): "La Pintura”, El año de Trajano. Hispania. El legado de Roma, 321-329, Zaragoza.

MUÑOZ FERNÁNDEZ, E., (2000): Las termas romanas de San Juan de Maliaño (Camargo, Cantabria) en Fernández Ochoa, C. y García Entero, V, (ed) Termas romanas en el occidente del Imperio. Coloquio Internacional, 229-235.

NEUDECKER, R. (1988): Die Skulpturen- Ausstattung römischer Villen in Italien, Mainz.

NOGUERA CELDRÁN, J.M. (2000): “Una aproximación a los programas decorativos de las villae béticas. El conjunto escultórico de El Ruedo (Almedinilla, Córdoba), Actas de la III Reunión sobre Escultura Romana en Hispania, 111-147, Madrid.

NUNES PEDROSO, R. (2000): "La praxis de la pintura mural de Emerita Augusta”, La pintura romana antigua. Actas del Coloquio Internacional, 73-100, Mérida (Mérida, 1996).

PATÓN LORCA, B. (2000): "La mansión de Materno", Carranque. Centro de Hispania romana, 83-91 (Alcalá de Henares, 2000-2001), Alcalá de Henares.

PÉREZ OLMEDO, E. (1997); "Sectilia pavimenta de época romana. El caso de Hispania”, Revista de Arqueología, 192, pp. 30-39, Madrid.

PÉREZ OLMEDO, E. (1999): "Sectilia peninsulares de época romana: un estado de la cuestión”, II Congreso de Arqueología Peninsular, Tomo IV, pp. 335 y ss. (Zamora, 1996), Alcalá de Henares.

POND, A. W. (1980): Primitive methods of working stone: based on experiments of Halvor L. Skavlem, Kraus Reprint, Millwood, NuevaYork.

REGUERAS GRANDE, F. Y OLMO, J DEL (1997): "La villa de Los Casares (Armuña, Segovia): Propuestas de lectura", Coloquio Internacional La Hispania de Teodosio, 2

RAMOS Ma. L. 1992 Una piscina bautismal de planta cruciforme descubierta en la villa romana de El Saucedo (Talavera de la Reina, Toledo), III Reunió ¿ Arqueología Cristiana Hispánica, 105-110 (Maó, 1988).

RODÁ, I., (1998): La explotación de las canteras en Hispania, Hispania. El Legado de Roma 113-118, Zaragoza.

RODÁ, I., (2001): Los mármoles de Carranque, Carranque. Centro de Hispania romana, 11-118, Alcalá de Henares.

SÁNCHEZ, Mã.; BLASCO, E. Y GUARDIOLA, A. (1986): Portus Ilicitanus. Datos para una síntesis, Santa Pola. 
SILLIÈRES, P. et alii., (2000): Las termas de la ciudad hispano-romana de Labitolosa: avance de su estudio, en Fernández Ochoa, C. Y García Entero, V, (ed) Termas romanas en el occidente del Imperio. Coloquio Internacional 163-169.

TORRECILLA AZNAR, A., et alii(1999): "Materiales de construcción en las termas de la Hispania romana, a propósito de los materiales hallados en la villa de El Saucedo (Talavera la Nueva, Toledo)", XXIV Congreso Nacional de Arqueología 397-416, Murcia (Cartagena, 1997).

TORRECILLA AZNAR, A., (1999): "Los pavimentos musivarios de la villa de El Saucedo (Talavera la Nueva, Toledo)", XXIV Congreso Nacional de Arqueología, 435-455, Murcia (Cartagena, 1997).

STOCKS, D.A. (1986): "Egyptian technology II: stone vessel manufacture”, Popular Archaeology, mayo de 1986, 14-18.
STOCKS, D.A. (1993): "Making stone vessels in ancient Mesopotamia and Egypt," Antiquity, 67, 596-603.

VAQUERIZO GIL, D. (1995) "El uso del mármol en la decoración arquitectónica y escultórica de villae cordobesas", en Noguera Celdrán, J.M. (coord.), Poblamiento rural en el sureste de Hispania, 81-103, Murcia (Jumilla, 1993).

VITRUVIO Los Diez Libros de Arquitectura. Ed. Iberia, Barcelona, 2000

ZUBER, A. (1956): "Techniques du travail des pierres dures dans l'Ancienne Egypte", Techniques et Civilisations, 29, 161-95. 